\title{
Adverse selection in the annuity market with sequential and simultaneous insurance demand
}

\author{
Johann K. Brunner and Susanne Pech *)
}

January 2005

Revised Version of Working Paper 0204, Department of Economics, University of Linz.

\section{Abstract}

This paper investigates the effect of adverse selection on the private annuity market in a model with two periods of retirement and two types of individuals, who differ in their life expectancy. In order to introduce the existence of limited-time pension insurance, we consider a model where for each period of retirement separate contracts can be purchased. Demand for the two periods can be decided either sequentially or simultaneously. We show that only a situation where all risk types choose sequential contracts can be an equilibrium and that this outcome is favourable for the long-living, but is unfavourable for the short-living individuals.

Keywords: annuity market, adverse selection, uncertain lifetime, equilibrium. JEL codes: D82, D91, G22.

*) Address: Department of Economics, University of Linz, Altenberger Straße 69, A-4040 Linz, Austria. Phone: +43-732-2468-8248, -8593, FAX: -9821. E-mail: johann.brunner@jku.at, susanne.pech@jku.at. 


\section{Introduction}

Social security systems, which in many industrialised countries are organised according to the pay-as-you-go method, are threatened by the ageing of the population due to a decrease in fertility and an increase in life expectancy. This problem is recognised by academics as well as by politicians, and several possible measures to maintain the financial stability of the system are suggested. One of these measures is a reduction of the pension payments, and it seems in fact unavoidable that it will be implemented to some degree. If this is the case, then a natural strategy for the individuals is to raise private provision for retirement, in particular by an increased purchase of life annuities. As governments want to prevent old-age poverty, they tend to encourage private pension insurance through tax incentives. ${ }^{1}$

However, there are concerns that the market for annuities does not offer a suitable supplement to the public pension system. One obvious argument is that it cannot incorporate redistribution, as the public system does for several reasons. Another argument concentrates on the phenomenon of adverse selection, which is a common problem that affects the efficient working of insurance markets. The present paper studies this problem in the context of specifically designed contracts for old-age insurance.

Generally, adverse selection occurs with asymmetric information, that is, when the insurer has less information than the individual as to the probability that the insured event occurs. In case of annuities, this means that companies have less information on life expectancy of an annuitant than the individual herself. As a consequence, returns from annuities cannot reflect individual life expectancy but only overall life expectancy, which in turn will induce high-risk individuals (that is, the long-living) to buy more annuities than low-risk individuals. This is the standard observation, discussed in various contributions to the literature (see, e.g., Pauly 1974, Eckstein et al. 1985, Abel 1986, Mitchell et al. 1999, Walliser 2000).

However, there is a further consequence of the adverse-selection problem, namely that the time structure of the benefits matters. Individuals with low life expectancy put less weight on pension payouts in later periods than individuals with high life expectancy. This aspect is

Tax incentives are granted in many industrialised countries, e. g. in Great Britain, U.S.A, Canada and Sweden. Moreover, the recent reform of social security in Germany aims at cutting public pensions and inducing individuals, by granting a tax release, to contribute four percent of income to private old-age insurance. Similarly, in Austria contributions to private old-age insurance are subsidised by a premium since 2000 . 
neglected in the usual overlapping-generations model with one working period and one period of retirement. But in reality the time of retirement must not be seen as a single, homogeneous period, for which provision can be made through a once-and-for-all contract only, with a fixed and constant (in nominal or real terms) payout. Planning individuals, being aware of some estimate of their life expectancy, will attempt to make provision in accordance with this estimate, which means that they want to use more differentiated instruments. In practice, they can buy an insurance contract with payouts increasing or decreasing over time, or they can buy a limited-time contract for the earlier phase of retirement and then use another instrument to provide for the rest of their lifetime. ${ }^{2}$

In order to analyse the consequences on the functioning of the annuity market of the fact that the time structure of the payouts matters, one has to extend the standard model by assuming that retirement consists of more periods and that provision can be made separately for each of them. Brunner and Pech (2005) introduce a model with one working period and two periods of retirement, where two groups of individuals with differing life expectancy buy an annuity contract which runs for the whole time of retirement, but with payouts possibly varying over time. ${ }^{3}$ It is shown that in this framework an equilibrium in the sense of NashCournot may but need not exist. ${ }^{4}$

In the present contribution we consider a similar model, but with different types of contracts. We again assume that individuals live for one working period and for at most two periods of retirement, but now contracts run for one period only; for the second period, a new contract has to be bought. By this formulation we take account of the fact that in reality term-insured pension contracts exist, which provide payouts only for a limited time, given that the individual is alive. For the rest some other form of provision must be made. ${ }^{5}$

2 Poterba (1997) emphasizes the importance of the wide range of different annuity products for the growth of the U.S. annuity market. He provides a typology of individual annuities with respect to the terms under which accumulated capital is dispersed during the liquidation phase. In particular, he distinguishes between two broad classes of individual annuities, that are deferred and immediate annuities, depending on whether there is a waiting period between the premium payment and the beginning of the annuity payouts or not.

The role of annuity contracts with escalating payouts in the U.K. annuity market is studied by Finkelstein and Poterba (2002).

3 Yagi and Nishigaki (1993) also employed a model with one working period and two periods of retirement in order to discuss optimal insurance demand of a representative individual. They showed that constant annuity payouts over time are inefficient, given that the individual rate of time preference differs from the interest rate. However, they did not consider the adverse-section problem and its impact on the existence of equilibria.

4 With these life annuities, firms can separate individuals according to their life expectancy by a variation of the payouts over time. In fact, only a separating equilibrium (compare Rothschild and Stiglitz 1976) can occur.

5 Townley and Boadway (1987) studied the functioning of the annuity market when individuals save out of their payouts from the limited-time pension contract. In contrast, we consider the case that they can buy a second annuity to provide for the remaining time. 
The important issue which we address is that individuals can choose between two strategies to provide for the second period of retirement: simultaneously, that is, individuals buy an additional contract already in the working period, or sequentially, that is, only those individuals who have survived to the first period of retirement, purchase an additional contract on the spot market. We show that in our model individuals in general chose only one of these alternatives, depending on the prices. However, in a first-best equilibrium, prices that then correspond to the individual life expectancies assume such values which make individuals indifferent between the two alternatives, because each provides the same consumption path over lifetime.

This is no longer true if asymmetric information, where prices are distorted by adverse selection, is introduced in our model. Then, under the assumption of price competition between annuity companies, the price for any contract is the same for both risk-groups, and only a situation where both groups buy the same type of second-period contract is feasible. Further, it turns out that the type of contract chosen to provide for the second period of retirement also affects the price of the first-period contract. In particular, we find that the two strategies have differing consequences for the welfare of the individuals, because they allow different consumption paths over the time of retirement: long-living individuals, who put more weight on consumption in the second period, prefer the regime when all individuals make sequential provision, while short-living individuals prefer the regime with simultaneous provision. Assuming that insurance companies can credibly commit in the working period to offer contracts at a pre-specified price, we find that only the former regime, favourable to the long-living individuals, represents a Nash-Cournot equilibrium. This result is puzzling because empirical evidence shows that in fact term-limited contracts represent a small share of annuity contracts (see, e.g., Mitchell et al., 1999). We discuss possible explanations for this puzzle in the concluding remarks.

In the following Section 2 we introduce the basic model and show that either simultaneous or sequential annuity contracts are chosen. We characterise demand in both cases. In Section 3 we analyse the consequences of adverse selection for annuity prices and for the existence of an equilibrium. Moreover, we study consumption and welfare of the individuals. Section 4 provides a discussion of the results. 


\section{Sequential and simultaneous demand for annuities}

Consider an economy with $\mathrm{H}$ individuals who live for a maximum of three periods $t=0,1,2$. In the working period $t=0$, each individual earns a fixed labour income $w_{0}$. At the end of period 0 she retires and lives for at most two further periods. Survival to the retirement period $t=1$ occurs with probability $\pi_{1}^{\mathrm{i}}, 0<\pi_{1}^{\mathrm{i}}<1$. In the same way, given that an individual is alive in period 1 , survival to period 2 occurs with probability $\pi_{2}^{i}, 0<\pi_{2}^{i}<1$.

Provision for old age can be made through three types of annuity contracts, which are offered by insurance companies:

- $A_{1}$ denotes the quantity of a contract, which is bought at a price $Q_{1}$ in working period 0 and offers an immediate payout $A_{1}$ in retirement period 1.

- $A_{2}$ denotes the quantity of a contract, which is bought at a price $Q_{2}$ in retirement period 1 and offers an immediate payout $A_{2}$ in retirement period 2.

- $D_{2}$ denotes the quantity of a contract, which is bought at a price $R_{2}$ in working period 0 and offers a deferred payout $D_{2}$ in retirement period 2 .

That is, each type of contract offers payouts for one period of retirement, but they differ in the date of purchase and the waiting period for the payout to begin: provision for retirement period 1 is made through $A_{1}$, while provision for retirement period 2 can be made through $A_{2}$ (bought by those only, who survive to retirement period 1 ) and/or through $\mathrm{D}_{2}$ (bought already in the working period). $\mathrm{Q}_{1}, \mathrm{Q}_{2}$ and $\mathrm{R}_{2}$ are the corresponding prices (premiums, resp.) per unit of annuity payout; the reciprocal of each price represents the rate of return on each contract type.

We assume that the individuals have no bequest motive, which means that saving is not an attractive strategy for them to provide for old-age. This follows from the fact that the rate of return of annuities is higher than the interest rate, as annuities allow to avoid (and redistribute) unintended bequests (see Yaari 1965). Further, in order to concentrate on the design of the annuity contracts and to simplify the analysis, the assumption is made that no public pension system exists. The budget equation of an individual i for the working period 0 is

$$
c_{0}^{i}=w_{0}-Q_{1} A_{1}^{i}-R_{2} D_{2}^{i} .
$$


Moreover, given that individual $i$ is alive in the retirement period 1 , she can spend an amount $Q_{2} A_{2}^{i}$ from her income $A_{1}^{i}$ in order to make additional provision for consumption in the retirement period 2 , and consumes an amount $c_{1}^{i}$. This gives us the budget equations for the two retirement periods $t=1,2$ :

$$
\begin{aligned}
& c_{1}^{i}=A_{1}^{i}-Q_{2} A_{2}^{i}, \\
& c_{2}^{i}=A_{2}^{i}+D_{2}^{i} .
\end{aligned}
$$

Preferences over lifetime consumption of an individual $i$ are time-separable and are represented by expected utility with a per-period utility function $u$ depending on consumption. An individual $i$ is confronted with the following two-stage decision problem: in the working period 0 , she decides on the quantities $A_{1}^{i}$ and $D_{2}^{i}$ of annuities, thus on her consumption level in period 0 and on her income $w_{t}^{i}$ in each of the two retirement periods $t=1,2$. For this decision she takes into account her optimal annuity demand $A_{2}^{i}$ and her optimal consumption levels in periods 1 and 2, about which she will decide in period 1 , given that then she is alive. Formally, this two-stage problem can be written as:

$$
\begin{aligned}
& t=0: \quad \max u\left(c_{0}^{i}\right)+\pi_{1}^{i} \varphi^{i}\left(A_{1}^{i}, Q_{2}, D_{2}^{i}\right), \\
& \text { s.t. }(2.1), \\
& t=1: \quad \max u\left(c_{1}^{i}\right)+\pi_{2}^{i} u\left(c_{2}^{i}\right),
\end{aligned}
$$

s. t. (2.2) and (2.3),

where $\varphi^{i}\left(A_{1}^{i}, Q_{2}, D_{2}^{i}\right) \equiv \max _{c_{1}^{i}, c_{2}^{i}, A_{2}^{i}}\left\{u\left(c_{1}^{i}\right)+\pi_{2}^{i} u\left(c_{2}^{i}\right) \mid c_{1}^{i}=A_{1}^{i}-Q_{2} A_{2}^{i}, c_{2}^{i}=D_{2}^{i}+A_{2}^{i}\right\}$.

Concerning the $A_{2}$-contract, we in fact assume that the individuals are informed about its price $\mathrm{Q}_{2}$ already in the working period 0 , in other words, that the insurance companies can credibly commit to offer those contracts at a price $\mathrm{Q}_{2}$ one period later. Otherwise $\varphi^{i}$ would not be well-defined. ${ }^{6}$ Further, we assume $u^{\prime}\left(c_{t}^{i}\right)>0, u^{\prime \prime}\left(c_{t}^{i}\right)<0$ and $\lim _{c \rightarrow 0} u^{\prime}(c)=\infty$. Notice that the specification of the decision problem means that the individuals do not discount future consumption for any reason other than risk aversion. ${ }^{7}$

6 We leave it to the concluding section to discuss the consequences of relaxing this assumption, e.g. that the individuals are uncertain in the working period about the future price level $\mathrm{Q}_{2}$, due to missing instruments of credible commitment by the firms.

7 To simplify notation, we do not include a time preference parameter explicitly in the utility function. To do so, would mean that a per-period discount factor enters (2.4) and (2.5) just in the same way as the survival probabilities. Nothing would change with the results. 
By inserting (2.1) into (2.4) and differentiating with respect to $A_{1}^{i}$ and $D_{2}^{i}$ as well as inserting (2.2) and (2.3) into (2.5) and differentiating with respect to $A_{2}^{i}$, we obtain the Kuhn-Tucker conditions of this maximization problem:

$$
\begin{aligned}
& -Q_{1} u^{\prime}\left(w_{0}-Q_{1} A_{1}^{i}-R_{2} D_{2}^{i}\right)+\pi_{1}^{i} \frac{\partial \varphi^{i}\left(A_{1}^{i}, Q_{2}, D_{2}^{i}\right)}{\partial A_{1}^{i}}=0 \\
& D_{2}^{i}>0 \quad \text { and } \quad-R_{2} u^{\prime}\left(w_{0}-Q_{1} A_{1}^{i}-R_{2} D_{2}^{i}\right)+\pi_{1}^{i} \frac{\partial \varphi^{i}\left(A_{1}^{i}, Q_{2}, D_{2}^{i}\right)}{\partial D_{2}^{i}}=0 \text { or } \\
& D_{2}^{i}=0 \quad \text { and }-R_{2} u^{\prime}\left(w_{0}-Q_{1} A_{1}^{i}-R_{2} D_{2}^{i}\right)+\pi_{1}^{i} \frac{\partial \varphi^{i}\left(A_{1}^{i}, Q_{2}, D_{2}^{i}\right)}{\partial D_{2}^{i}} \leq 0 \\
& A_{2}^{i}>0 \text { and }-Q_{2} u^{\prime}\left(A_{1}^{i}-Q_{2} A_{2}^{i}\right)+\pi_{2}^{i} u^{\prime}\left(D_{2}^{i}+A_{2}^{i}\right)=0 \text { or } \\
& A_{2}^{i}=0 \quad \text { and } \quad-Q_{2} u^{\prime}\left(A_{1}^{i}-Q_{2} A_{2}^{i}\right)+\pi_{2}^{i} u^{\prime}\left(D_{2}^{i}+A_{2}^{i}\right) \leq 0,
\end{aligned}
$$

where by application of the Envelope Theorem

$$
\begin{aligned}
& \frac{\partial \varphi^{i}\left(A_{1}^{i}, Q_{2}, D_{2}^{i}\right)}{\partial A_{1}^{i}}=u^{\prime}\left(c_{1}^{i}\right), \\
& \frac{\partial \varphi^{i}\left(A_{1}^{i}, Q_{2}, D_{2}^{i}\right)}{\partial D_{2}^{i}}=\pi_{2}^{i} u^{\prime}\left(C_{2}^{i}\right) .
\end{aligned}
$$

Obviously, an individual $i$ always has a positive annuity demand $A_{1}^{i}$ for the first-period contract, since this is the only possibility to provide for first-period consumption. But she can decide either to buy the immediate annuity contract (i.e. $A_{2}^{i}>0, D_{2}^{i}=0$ ) or the deferred contract (i.e. $A_{2}^{i}=0, D_{2}^{i}>0$ ) or both kind of contracts (i.e. $A_{2}^{i}>0, D_{2}^{i}>0$ ) in order to make provision for consumption in the second retirement period. The following Lemma shows that the latter case is in general excluded.

Lemma 1: In general, it is not optimal for an individual $i$ to choose both $D_{2}^{i}>0$ and $A_{2}^{i}>0$. The inequality $Q_{1} Q_{2}>R_{2}\left(Q_{1} Q_{2}<R_{2}\right)$ implies $D_{2}^{i}>0$ and $A_{2}^{i}=0 \quad\left(A_{2}^{i}>0\right.$ and $D_{2}^{i}=0$, resp.).

Proof: See the Appendix.

In order to receive one unit of payout in the second retirement period, the individual has to invest $Q_{2}$ units into the $A_{2}$-contract in the first retirement period and hence $Q_{1} Q_{2}$ units of 
income into the $A_{1}$-contract in the working period. On the other hand, $R_{2}$ units of income invested (in the working period) into the $\mathrm{D}_{2}$-contract transforms into one unit of payout in the second retirement period. Therefore, the decisive relation is $Q_{1} Q_{2} \gtrless R_{2}$, whether provision for the second period of retirement is made through an $A_{2}$ - or a $D_{2}$-contract. Only in case of $\mathrm{Q}_{1} \mathrm{Q}_{2}=\mathrm{R}_{2}$, the individuals would be indifferent between both types of contracts. For the remainder of this section we rule out this specific parameter constellation, but we distinguish between the two different situations whether an individual expresses annuity demand sequentially or simultaneously. In the first case of sequential annuity demand, the purchase of $A_{t}^{i}, t=1,2$, arises from a two-stage decision process, whose optimal solution is characterised by (2.6) and (2.8a). In the second case of simultaneous annuity demand, the purchased amounts $A_{1}^{i}, D_{2}^{i}$ are determined by the first-order conditions (2.6) and (2.7a).

The following two Lemmas characterise how prices and the survival probabilities influence annuity demand in both cases.

\section{Lemma 2:}

(i) In case of sequential annuity demand, i.e. $A_{1}^{i}>0, A_{2}^{i}>0, D_{2}^{i}=0$, we have

$$
\begin{array}{ll}
\frac{\partial A_{1}^{i}\left(Q_{1}, Q_{2}\right)}{\partial Q_{1}}<0, & \frac{\partial A_{2}^{i}\left(Q_{1}, Q_{2}\right)}{\partial Q_{1}}<0, \\
\frac{\partial A_{1}^{i}\left(Q_{1}, Q_{2}\right)}{\partial Q_{2}}>0, \text { if } \varepsilon_{2}^{i}>-1, & \frac{\partial A_{2}^{i}\left(Q_{1}, Q_{2}\right)}{\partial Q_{2}}<0,
\end{array}
$$

where $\varepsilon_{2}^{i}$ denotes the price elasticity of annuity demand $A_{2}^{i}$ for constant $A_{1}^{i}$.

(ii) In case of simultaneous annuity demand, i.e. $A_{1}^{i}>0, A_{2}^{i}=0, D_{2}^{i}>0$, we have:

$$
\begin{array}{ll}
\frac{\partial A_{1}^{i}\left(Q_{1}, R_{2}\right)}{\partial Q_{1}}<0, & \frac{\partial D_{2}^{i}\left(Q_{1}, R_{2}\right)}{\partial Q_{1}} \lesseqgtr 0 \text { if } \eta_{1}^{i} \gtreqless-1, \\
\frac{\partial A_{1}^{i}\left(Q_{1}, R_{2}\right)}{\partial R_{2}} \lesseqgtr 0 \text { if } \eta_{2}^{i} \gtreqless-1, & \frac{\partial D_{2}^{i}\left(Q_{1}, R_{2}\right)}{\partial R_{2}}<0,
\end{array}
$$

where $\eta_{1}^{i}$ denotes the price elasticity of annuity demand $A_{1}^{i}$ for constant $D_{2}^{i}$ and $\eta_{2}^{i}$ the price elasticity of annuity demand $D_{2}^{i}$ for constant $A_{1}^{i}$.

Proof: See Appendix. 
We find the usual result that demand for an annuity contract decreases, if its price rises. However, demand may but need not react in the same way, if the price of the other contract rises. The reasoning for the cross-price effects in case of sequential demand is the following: An increase in $Q_{1}$ reduces demand for the $A_{1}$-contract and hence income $w_{1}^{i}=A_{1}^{i}$ in retirement period 1 , out of which the $A_{2}$-contract has to be financed. The individual adapts to the decrease in $w_{1}^{i}$ (which would mean a reduction of $c_{1}^{i}$ in case of unchanged $A_{2}^{i}$ ) by decreasing demand for the $A_{2}$-contract (and thus consumption $c_{2}^{i}$ as well). The cross-price effect $\partial A_{1}^{i} / \partial Q_{2}$ follows from related arguments: In this case, it is essential how a change in $\mathrm{Q}_{2}$ affects consumption $c_{1}^{i}$ holding $A_{1}^{i}$ for the moment. Note that, although $\partial A_{2}^{i} / \partial Q_{2}<0$, obviously, the expenditures $Q_{2} A_{2}^{i}$ for the $A_{2}$-contract and hence $c_{1}^{i}$ for fixed $A_{1}^{i}$ may de- or increase, depending on the price elasticity $\varepsilon_{2}^{i}$ of demand $A_{2}^{i}$ for fixed $w_{1}^{i}=A_{1}^{i}$. If $Q_{2}$ increases and $\varepsilon_{2}^{i}$ is larger than -1 , then $Q_{2} A_{2}^{i}$ increases, which means a reduction of $c_{1}^{i}$. Then it is optimal for the individual to shift part of the reduction to the working period 0 by decreasing $c_{0}^{i}$ and increasing demand for the $A_{1}$-contract. By the same argument, it is optimal for an individual to leave demand for the $A_{1}$-contract unchanged, if $\varepsilon_{2}^{i}=-1$, and to decrease demand $A_{1}^{i}$, if $\varepsilon_{2}^{i}<-1 A_{1}^{i}$.

Analogous considerations apply for the cross-price effects in the case of simultaneous demand: The relevant issue is how an increase of the price $Q_{1}$ and $R_{2}$, resp., directly affects expenditures $Q_{1} A_{1}^{i}$ and $R_{2} D_{2}^{i}$, resp. (with demand for the other contract held constant). If expenditures increase $\left(\eta_{t}^{i}>-1\right)$, then part of the implied reduction of consumption $c_{0}^{i}$ in the working period is shifted to the respective other period through a reduction of the corresponding annuity demand; and analogous for elasticities $\eta_{t}^{i} \leq-1$.

\section{Lemma 3:}

(i) In case of sequential annuity demand, i.e. $A_{1}^{i}>0, A_{2}^{i}>0, D_{2}^{i}=0$, we have

$$
\begin{array}{ll}
\frac{\partial A_{1}^{i}\left(Q_{1}, Q_{2}\right)}{\partial \pi_{1}^{i}}>0, & \frac{\partial A_{2}^{i}\left(Q_{1}, Q_{2}\right)}{\partial \pi_{1}^{i}}>0 \\
\frac{\partial A_{1}^{i}\left(Q_{1}, Q_{2}\right)}{\partial \pi_{2}^{i}}>0, & \frac{\partial A_{2}^{i}\left(Q_{1}, Q_{2}\right)}{\partial \pi_{2}^{i}}>0 .
\end{array}
$$

(ii) In case of simultaneous annuity demand, i.e. $A_{1}^{i}>0, A_{2}^{i}=0, D_{2}^{i}>0$, we have

$$
\frac{\partial A_{1}^{i}\left(Q_{1}, R_{2}\right)}{\partial \pi_{1}^{i}}>0, \quad \frac{\partial D_{2}^{i}\left(Q_{1}, R_{2}\right)}{\partial \pi_{1}^{i}}>0
$$




$$
\frac{\partial A_{1}^{i}\left(Q_{1}, R_{2}\right)}{\partial \pi_{2}^{i}}<0, \quad \frac{\partial D_{2}^{i}\left(Q_{1}, R_{2}\right)}{\partial \pi_{2}^{i}}>0
$$

Proof: See Appendix.

We find that generally annuity demand reacts positively, if any probability of survival increases. However, there is an essential difference between the two cases, which concerns the cross effect of $\pi_{2}^{i}$ on the first-period contract. With sequential decisions, an increase of the probability of survival to the second period of retirement increases demand $A_{1}^{i}$, because this allows to buy more insurance for period 2. On the other hand, with simultaneous decisions an increase of $\pi_{2}^{i}$ means that insurance for the first period of retirement is substituted by insurance for the second period of retirement. Note further that an increase in $\pi_{1}^{i}$ clearly increases the probability $\pi_{1}^{i} \pi_{2}^{i}$ of survival to the second period as well, hence demand for the second-period contracts rises in both cases.

\section{Adverse selection in the annuity market}

Having described the two possible strategies to provide for old age, namely through sequential and simultaneous annuity demand, we now study the implications of asymmetric information on the functioning of the annuity market. Let from now the otherwise identical individuals be divided into two groups $\mathrm{i}=\mathrm{L}, \mathrm{H}$, characterised by different risks of a long life, i.e. by different probabilities of survival $\pi_{t}^{H}>\pi_{t}^{L}$ for $t=1,2$. Let $\gamma_{0}$ and $1-\gamma_{0}$, resp., denote the shares of the high-risk and low-risk individuals in period 0 , with $0<\gamma_{0}<1$.

First, as a point of reference we consider the case that there is perfect information about the survival probabilities. Then, obviously, perfect competition among the insurance firms, ensures that each type of individuals receive their individually fair contracts. An annuity is said to be individually fair, if expected payouts equal its price. This requires for the $A_{1^{-}}, A_{2^{-}}$ and $\mathrm{D}_{2}$-contracts that the respective conditions

$$
\begin{aligned}
& \mathrm{Q}_{\mathrm{t}}^{\mathrm{i}}-\pi_{\mathrm{t}}^{\mathrm{i}}=0, \mathrm{t}=1,2, \\
& \mathrm{R}_{2}^{\mathrm{i}}-\pi_{1}^{\mathrm{i}} \pi_{2}^{\mathrm{i}}=0 .
\end{aligned}
$$


hold. Clearly, this implies that the annuity companies make zero expected profits, given that identical individuals buy these contracts.

Lemma 4: Given individually fair contracts, any individual is indifferent between choosing an $A_{2}$ - or $D_{2}$-contract for the second period of retirement. She chooses the same level of consumption in every period $t=0,1,2$.

Proof: The zero-profit conditions (3.1), (3.2) imply $\mathrm{Q}_{1} \mathrm{Q}_{2}=\mathrm{R}_{2}$, which is the condition for indifference, as mentioned after Lemma 1. Considering (2.6) - (2.10), one observes that the zero-profit conditions also imply $u^{\prime}\left(c_{0}^{i}\right)=u^{\prime}\left(c_{1}^{i}\right)=u^{\prime}\left(c_{2}^{i}\right)$, irrespective of the chosen contracts.

Q.E.D.

In a first-best world, where every individual can buy an annuity contract whose price is precisely adjusted to her life expectancy, it does not matter, which type of contract is chosen for provision for the second period of retirement. Each offers an optimal smoothing of consumption. However, in reality, lack of information prevents the supply of first-best contracts.

We introduce asymmetric information into the model in the usual way: The probabilities $\pi_{\mathrm{t}}^{\mathrm{i}}$ and $\gamma_{0}$ are public information, known by the annuity companies. But it is the private information for each individual to know her type, i.e. her probability of survival. As a consequence, there is an adverse-selection problem in the annuity market. Moreover, we assume that there is perfect competition among the annuity companies and that they cannot monitor whether consumers buy annuities from other insurance companies, which seems to be a reasonable assumption frequently made for the annuity market (see e.g. Pauly 1974, Abel 1986, Brugiavini 1993, Walliser 2000, Brunner and Pech 2005). ${ }^{8}$ This assumption means that firms fix the price of a contract and individuals can buy as many annuities of each contract as they want. It follows that in equilibrium for each contract only one price, paid by both types of individuals, can exist in each period $t=1,2$. As a consequence, the first-best

Price and quantity competition, where firms offer a number of different contracts which specify both a price and a quantity, needs as a prerequisite that individuals can buy at most one contract. This is regarded to be appropriate for some insurance markets, e.g. insurance against accidents, but not for the annuity market. However, price and quantity competition generates the possibility of a separating equilibrium (see Rothschild and Stiglitz, 1976; Wilson, 1977). 
solution is unsustainable, because the individually fair prices of the $A_{1^{-}}, A_{2^{-}}$and $D_{2}$-contract as defined by (3.1) and (3.2) are lower for type-L individuals than for type-H individuals. ${ }^{9}$

Both types of individuals buy the same contract, which is called a pooling situation. Moreover, the same argument implies that only a situation, where both groups use the same type of contract in order to provide for the second period of retirement, can prevail. That is, either both groups use the $A_{2}$-contract for the second period of retirement or both groups use the $D_{2}$-contract. This follows from the fact that only one price $Q_{1}$ for the first-period contract $A_{1}$ can exist, and that each group chooses either the $A_{2^{-}}$or the $D_{2}$-contract, depending on whether $\mathrm{Q}_{1} \mathrm{Q}_{2} \gtrless \mathrm{R}_{2}$ (see Lemma 1). Thus we distinguish between two different regimes, where all individuals demand either sequential or simultaneous pooling contracts:

$$
\begin{array}{lll}
\text { sequential regime: } & A_{1}^{i}>0, A_{2}^{i}>0, D_{2}^{i}=0 & \text { for } i=L, H, \\
\text { simultaneous regime: } & A_{1}^{i}>0, A_{2}^{i}=0, D_{2}^{i}>0 & \text { for } i=L, H .
\end{array}
$$

As a next step we discuss, to which extent the adverse-selection problem matters in the two regimes, that is, whether individuals with a long life expectancy buy a larger amount of the different types of contracts.

\section{Lemma 5:}

(i) In the sequential regime, for any prices $\mathrm{Q}_{1}, \mathrm{Q}_{2}$, an individual with high survival probabilities demands larger quantities of annuities than an individuals with low survival probabilities, i. e. $A_{t}^{H}\left(Q_{1}, Q_{2}\right)>A_{t}^{L}\left(Q_{1}, Q_{2}\right), t=1,2$.

(ii) In the simultaneous regime, for any prices $\mathrm{Q}_{1}, \mathrm{R}_{2}$, an individual with high survival probabilities demands a larger quantity $D_{2}$ than an individual with low survival probabilities, i.e. $D_{2}^{H}\left(Q_{1}, R_{2}\right)>D_{2}^{L}\left(Q_{1}, R_{2}\right)$. The ratio of demand for the $A_{1}$-contract is undetermined.

Proof: Follows immediately from Lemma 3 and $\pi_{t}^{\mathrm{L}}<\pi_{t}^{\mathrm{H}}, t=1,2$.

9 That both types of individuals buy the same contract could be called a pooling situation. However, in a strict sense, this term refers to a framework where in principle the groups could be separated through appropriate instruments, e.g. through price and quantity competition. 
If the problem of adverse selection is defined by the criterion that the ratio of aggregate group- $\mathrm{H}$ demand to aggregate group- $\mathrm{L}$ demand exceeds the ratio of group shares $\gamma_{0} /\left(1-\gamma_{0}\right)$, we find that this problem certainly occurs for both contracts in the sequential regime; in the simultaneous regime it occurs for the second-period contract, while for the first-period contract it is mitigated by the fact that an increase of $\pi_{2}^{i}$ decreases demand for the $\mathrm{A}_{1}$-contract.

\subsection{Prices in both regimes}

The consequence of the over-representation of high-risk individuals among aggregate annuity demand is that in equilibrium insurance companies charge a price which is higher than the actuarially fair price corresponding to the average probability of survival of the population. The respective prices are determined by the condition that, due to the assumption of perfect competition in the annuity market, the expected profits of a contract, bought by both groups $L$ and $H$, must be equal to zero. As $\pi_{t}^{i}$ is the expected payout for group $i$, the zero-profit condition for the $A_{1}$-contract in either regime reads

$$
\left(1-\gamma_{0}\right) \mathrm{A}_{1}^{\mathrm{L}}\left(\mathrm{Q}_{1}-\pi_{1}^{\mathrm{L}}\right)+\gamma_{0} \mathrm{~A}_{1}^{\mathrm{H}}\left(\mathrm{Q}_{1}-\pi_{1}^{\mathrm{H}}\right)=0
$$

Since type- $\mathrm{H}$ individuals have a higher probability to survive to retirement period 1 , i.e. $\pi_{1}^{\mathrm{H}}>\pi_{1}^{\mathrm{L}}$, their share in period 1 will rise to

$$
\gamma_{1} \equiv \frac{\gamma_{0} \pi_{1}^{\mathrm{H}}}{\gamma_{0} \pi_{1}^{\mathrm{H}}+\left(1-\gamma_{0}\right) \pi_{1}^{L}},
$$

while the share of type- $L$ individuals reduces to $\left(1-\gamma_{1}\right)$. Thus relatively more type-H individuals will buy an $\mathrm{A}_{2}$-contract for the retirement period 2 , and its zero-profit condition reads

$$
\left(1-\gamma_{1}\right) A_{2}^{\mathrm{L}}\left(Q_{2}-\pi_{2}^{\mathrm{L}}\right)+\gamma_{1} \mathrm{~A}_{2}^{\mathrm{H}}\left(\mathrm{Q}_{2}-\pi_{2}^{\mathrm{H}}\right)=0
$$

In the simultaneous regime, where the $A_{1}$-contract is supplemented by the $D_{2}$-contract, the expected payout from the latter is $\pi_{1}^{i} \pi_{2}^{i}$, and the zero-profit condition reads

$$
\left(1-\gamma_{0}\right) D_{2}^{\mathrm{L}}\left(R_{2}-\pi_{1}^{\mathrm{L}} \pi_{2}^{\mathrm{L}}\right)+\gamma_{0} \mathrm{D}_{2}^{\mathrm{H}}\left(\mathrm{R}_{2}-\pi_{1}^{\mathrm{H}} \pi_{2}^{\mathrm{H}}\right)=0
$$


Note that the prices cannot be computed explicitly from (3.3), (3.5) and (3.6), because in each equation annuity demand depends on the respective prices. Nevertheless, if one takes the ratio of aggregate demand of group $\mathrm{H}$ to that of group $\mathrm{L}$ as exogenous for the moment, one observes that the respective price is higher, the larger this ratio.

For a more detailed study of the functioning of the annuity market, when there is asymmetric information and annuity companies can offer both kinds of second-period contracts, namely immediate as well as deferred annuities, we assume from now on that instantaneous utility is logarithmic, i.e.

$$
u\left(c_{t}^{i}\right)=\ln \left(c_{t}^{i}\right) \text { for } t=0,1,2
$$

Logarithmic utility has the convenient property that most cross-price effects are zero (as $\varepsilon_{2}^{i}, \eta_{t}^{i}=-1$, see Lemma 2 ). This property keeps explicit computation of the zero-profit prices in either regime simple. ${ }^{10}$ In the following, a tilde refers to the sequential regime, while a bar refers to the simultaneous regime.

Sequential regime: The conditions (2.6) and (2.8a) together with (2.9) determine annuity demand $\tilde{\mathrm{A}}_{1}^{i}$ and $\tilde{\mathrm{A}}_{2}^{i}$ for each single-period immediate contract. For logarithmic utility one computes

$$
\tilde{A}_{1}^{i}=\frac{\left(1+\pi_{2}^{i}\right) X^{i}}{Q_{1}}, \quad \tilde{A}_{2}^{i}=\frac{\pi_{2}^{i} X^{i}}{Q_{1} Q_{2}} .
$$

where $X^{i} \equiv \pi_{1}^{i} w_{0} /\left(1+\pi_{1}^{i}+\pi_{1}^{i} \pi_{2}^{i}\right)$. Solving (3.3) and (3.5), together with (3.8), gives

$$
\widetilde{\mathrm{Q}}_{1} \equiv \frac{\pi_{1}^{\mathrm{L}}+\pi_{1}^{\mathrm{H}} \tilde{\rho}_{1}}{1+\tilde{\rho}_{1}}, \quad \widetilde{\mathrm{Q}}_{2} \equiv \frac{\pi_{2}^{\mathrm{L}}+\pi_{2}^{\mathrm{H}} \tilde{\rho}_{2}}{1+\tilde{\rho}_{2}},
$$

where $\tilde{\rho}_{t}, t=1,2$, denotes the the ratio of annuity demand of both groups:

$$
\tilde{\rho}_{1} \equiv \frac{\gamma_{0} \tilde{A}_{1}^{H}}{\left(1-\gamma_{0}\right) \tilde{A}_{1}^{L}}, \quad \tilde{\rho}_{2} \equiv \frac{\gamma_{1} \tilde{A}_{2}^{H}}{\left(1-\gamma_{1}\right) \tilde{A}_{2}^{L}},
$$

10 In the concluding section we will discuss the consequences for our results of assuming a general utility function. 
Simultaneous regime: By use of (A20), (A20) in the Appendix and (3.7) we obtain annuity demand $\bar{A}_{1}^{i}$ for the first-period contract and annuity demand $\bar{D}_{2}^{i}$ for the second-period contract as

$$
\overline{\mathrm{A}}_{1}^{\mathrm{i}}=\frac{\mathrm{X}^{\mathrm{i}}}{\mathrm{Q}_{1}}, \quad \overline{\mathrm{D}}_{2}^{\mathrm{i}}=\frac{\pi_{2}^{\mathrm{i}} \mathrm{X}^{\mathrm{i}}}{\mathrm{R}_{2}}
$$

Solving (3.3) and (3.6), together with (3.11) yields

$$
\overline{\mathrm{Q}}_{1} \equiv \frac{\pi_{1}^{\mathrm{L}}+\pi_{1}^{\mathrm{H}} \bar{\rho}_{1}}{1+\bar{\rho}_{1}}, \quad \overline{\mathrm{R}}_{2} \equiv \frac{\pi_{1}^{\mathrm{L}} \pi_{2}^{\mathrm{L}}+\pi_{1}^{\mathrm{H}} \pi_{2}^{\mathrm{H}} \bar{\rho}_{2}}{1+\bar{\rho}_{2}}
$$

where $\bar{\rho}_{t}, t=1,2$, is defined by

$$
\bar{\rho}_{1} \equiv \frac{\gamma_{0} \bar{A}_{1}^{H}}{\left(1-\gamma_{0}\right) \bar{A}_{1}^{L}}, \quad \bar{\rho}_{2} \equiv \frac{\gamma_{0} \bar{D}_{2}^{H}}{\left(1-\gamma_{0}\right) \bar{D}_{2}^{L}} .
$$

With these formulas, we are able to compare the composition of aggregate demand and the prices in the two regimes.

Lemma 6: The following relations hold

(i) between the ratios of aggregate annuity demand of group $H$ to that of group $L$ for the different types of contracts: $\tilde{\rho}_{1}>\bar{\rho}_{1}, \tilde{\rho}_{2}>\bar{\rho}_{2}, \tilde{\rho}_{1}<\bar{\rho}_{2}$.

(ii) between the prices for the different types of contracts: $\widetilde{\mathrm{Q}}_{1}>\overline{\mathrm{Q}}_{1}, \widetilde{\mathrm{Q}}_{2}>\overline{\mathrm{R}}_{2}, \widetilde{\mathrm{Q}}_{1} \widetilde{\mathrm{Q}}_{2}<\overline{\mathrm{R}}_{2}$.

Proof: See Appendix.

The inequalities $\widetilde{\rho}_{1}>\bar{\rho}_{1}$ and $\widetilde{\mathrm{Q}}_{1}>\overline{\mathrm{Q}}_{1}$ indicate that the adverse-selection problem for the first-period contract is more severe in the sequential regime than in the simultaneous regime (compare the discussion after Lemma 5). The intuitive reason for this result is the following: in the simultaneous regime, annuity demand $\overline{\mathrm{A}}_{1}^{\mathrm{i}}$ for the first-period contract satisfies only the need for future consumption in period 1 . In contrast, in the sequential regime, annuity demand $\widetilde{A}_{1}^{i}$ for the first-period contract has to satisfy the need for future consumption in both retirement periods 1 and 2 , since part of the payouts $\tilde{A}_{1}^{i}$ is used for the demand $\tilde{A}_{2}^{i}$. Highrisk individuals choose a higher demand $\widetilde{A}_{2}^{i}$ than low risk-individuals (see Lemma 5), which in turn intensifies adverse selection for the first-period contract. 
The essential reason, why $\widetilde{\rho}_{2}>\bar{\rho}_{2}$ and $\widetilde{Q}_{2}>\bar{R}_{2}$ hold, is that from period 0 (when the $D_{2^{-}}$ contract is bought) to period 1 (when the $A_{2}$-contract is bought) the share of the high-risk individuals in the population rises, i.e. $\gamma_{0}<\gamma_{1}$, because of $\pi_{1}^{\mathrm{L}}<\pi_{1}^{\mathrm{H}}$. As the ratio of individual demand is the same for both contracts in case of logarithmic utility $\left[\tilde{A}_{2}^{H} / \widetilde{A}_{2}^{L}=\bar{D}_{2}^{H} / \bar{D}_{2}^{L}\right.$, see (3.8) and (3.11)], these shares indeed are responsible for the higher price of the $A_{2}$-contract compared to that of the $D_{2}$-contract.

A further important result of Lemma 6 is the inequality $\widetilde{\mathrm{Q}}_{1} \widetilde{\mathrm{Q}}_{2}<\overline{\mathrm{R}}_{2}$. Remember that $\widetilde{\mathrm{Q}}_{1} \widetilde{\mathrm{Q}}_{2}$ is the price in the sequential regime which must be paid in the working period in order to receive one unit of payout in the second retirement period. It is smaller than $\bar{R}_{2}$, the corresponding price in the simultaneous regime. This can be explained by the fact that in the former regime provision for period 2 is made via the first-period contract $A_{1}$, which is bought by the low-risk individuals to a larger extent than the $D_{2}$-contract (note that $\tilde{\rho}_{1}<\bar{\rho}_{2}$ ). In other words, in the sequential regime the high-risk individuals, when insuring for the second period, benefit from being for the first period in a pool with the low-risk individuals, who put particular weight on insurance for this period, due to their short life expectancy. In a sense, this result represents the counterpart to the above argument explaining why $\widetilde{\mathrm{Q}}_{1}>\overline{\mathrm{Q}}_{1}$.

\subsection{Equilibrium}

Now we turn to an analysis of whether either or both of the two regimes constitute an equilibrium. We call a set of contracts an equilibrium in the sense of Nash-Cournot, if together with annuity demand of both groups $\mathrm{i}=\mathrm{L}, \mathrm{H}$ the respective zero-profit condition for each contract is fulfilled and if no other contract exists, which is preferred by at least one group $\mathrm{i} \in\{L, H\}$ and which allows a nonnegative profit.

Proposition 1: The sequential contracts with prices $\widetilde{\mathrm{Q}}_{1}, \widetilde{\mathrm{Q}}_{2}$ represent an equilibrium.

Proof: If the $A_{1}$-contract were offered at a price $Q_{1}<\widetilde{Q}_{1}$, both groups would buy that and the insurance company would make a loss. (Note that $\tilde{\rho}_{1}$ is independent of $Q_{1}$ (see (3.10)), hence $\widetilde{\mathrm{Q}}_{1}$ is the unique payout which fulfils the zero-profit condition (3.5)). By the same argument, an insurance company offering an $\mathrm{A}_{2}$-contract with price $\mathrm{Q}_{2}<\widetilde{\mathrm{Q}}_{2}$ would make a loss. 
Finally, if an alternative $\mathrm{D}_{2}$-contract with a price $\mathrm{R}_{2}<\widetilde{\mathrm{Q}}_{1} \widetilde{\mathrm{Q}}_{2}$ was offered, again both groups would buy that (see Lemma 1) and the insurance company would make a loss. This follows from the fact that $\bar{R}_{2}$ does not depend on $Q_{1}$ (see (3.12)) and the zero-profit conditions imply $\overline{\mathrm{R}}_{2}>\widetilde{\mathrm{Q}}_{1} \widetilde{\mathrm{Q}}_{2}$ (see Lemma 6 (ii)).

Q.E.D.

Proposition 2: The simultaneous contracts with prices $\overline{\mathrm{Q}}_{1}, \overline{\mathrm{R}}_{2}$ do not constitute an equilibrium.

Proof: Given the simultaneous contracts, an insurance company can additionally offer a sequential $\mathrm{A}_{2}$-contract with price $\widetilde{\mathrm{Q}}_{2}$. Indeed, as $\tilde{\rho}_{2}$ and consequently $\widetilde{\mathrm{Q}}_{2}$ do not depend on $\mathrm{Q}_{1}$ [see (3.9) and (3.10)], firms make a nonnegative profit by this offer. We know that $\overline{\mathrm{Q}}_{1}<\widetilde{\mathrm{Q}}_{1}$ and $\widetilde{\mathrm{Q}}_{1} \widetilde{\mathrm{Q}}_{2}<\overline{\mathrm{R}}_{2}$ from Lemma 6. Hence $\overline{\mathrm{Q}}_{1} \widetilde{\mathrm{Q}}_{2}<\overline{\mathrm{R}}_{2}$, which means that any individual will accept the offer (see Lemma 1 ).

Q.E.D.

Remember that it is in the working period 0 when an individual opts either for the $D_{2}$ - or the $\mathrm{A}_{2}$-contract. Hence, the assumption made in Section 2.1 that in period 0 insurance companies can credibly commit to offer the sequential contract with price $\widetilde{\mathrm{Q}}_{2}$ one period later, is essential for these results. This issue will be discussed further in the concluding section 4.

Intuitively there are two reasons why the sequential regime with prices $\widetilde{\mathrm{Q}}_{1}, \widetilde{\mathrm{Q}}_{2}$ constitutes an equilibrium: i) From the above results we know that the sequential regime allows provision for the second retirement period at a lower price. Thus, it is plausible that no better $D_{2}$-contract can be offered without making a loss. ii) No lower price than $\widetilde{Q}_{1}$ can be granted for the $A_{1}$ contract, in view of the fact that individuals use part of the returns from this $A_{1}$-contract to provide for the second period via the $\mathrm{A}_{2}$-contract.

Conversely, the simultaneous regime with prices $\overline{\mathrm{Q}}_{1}, \overline{\mathrm{R}}_{2}$ is not an equilibrium, because firms can additionally offer an $A_{2}$-contract at a price $\widetilde{Q}_{2}$, which combined with the existing $A_{1}$ contract with price $\overline{\mathrm{Q}}_{1}$ allows provision for both retirement periods at a lower price. (Obviously however, the existing $A_{1}$-contract with return $\bar{Q}_{1}$ would make a loss in this case, because $\widetilde{Q}_{1}$ is the lowest price compatible with sequential contracts.) 


\subsection{Welfare analysis}

In a final step of our analysis, we study welfare of both types of individuals $\mathrm{i}=\mathrm{L}, \mathrm{H}$ in the two regimes, in order to find out whether the equilibrium outcome - the sequential contracts - is a favourable solution for one or both risk groups. We start the analysis by comparing optimal consumption levels in each regime.

\section{Lemma 7:}

(i) In working period 0 , the consumption level $c_{0}^{i}$ of any individual $i L, H$, is the same irrespective whether she chooses sequential or simultaneous annuity contracts.

(ii) In retirement period 1 , consumption of any individual $\mathrm{i}=\mathrm{L}, \mathrm{H}$, is lower in the sequential regime than in the simultaneous regime, i.e. $c_{1}^{i}\left(\widetilde{Q}_{1}, \widetilde{Q}_{2}\right)<c_{1}^{i}\left(\bar{Q}_{1}, \bar{R}_{2}\right)$ for $i=L, H$.

(iii) In retirement period 2, consumption of any individual $i=L, H$, is higher in the sequential regime than in the simultaneous regime, i.e. $c_{2}^{i}\left(\widetilde{Q}_{1}, \widetilde{Q}_{2}\right)>c_{2}^{i}\left(\bar{Q}_{1}, \bar{R}_{2}\right)$ for $i=L, H$.

Proof: See Appendix.

Note that part (i) of Lemma 7 holds for any contracts with prices $Q_{1}, Q_{2}$ and $Q_{1}, R_{2}$, since for logarithmic utility the expenditures for annuities in working period do not depend on prices, i.e $Q_{1} \tilde{A}_{1}^{i}=Q_{1} \bar{A}_{1}^{i}+R_{2} \bar{D}_{2}^{i}$ for any $Q_{1}, Q_{2}, R_{2}$. Hence it is optimal for an individual to invest the same amount $w_{0}-c_{0}^{i}$ into old-age provision in either regime. However, the prices influence the level of consumption in both retirement periods. Particularly, we find that the relations $\widetilde{\mathrm{Q}}_{1}>\overline{\mathrm{Q}}_{1}, \widetilde{\mathrm{Q}}_{1} \widetilde{\mathrm{Q}}_{2}<\overline{\mathrm{R}}_{2}$, as shown in Lemma 6 (ii), are in fact decisive for the distribution of consumption over the two periods of retirement in the two regimes. With the sequential regime, more consumption is postponed to the second period of retirement, while the simultaneous regime induces individuals to consume relatively more in the first period of retirement. Altogether, it follows that it is unclear from the results of Lemma 7, in which regime an individual of type $i$ is better off. In order to answer this question, we first determine the consumption possibility curves for period 1 and 2 .

The consumption possibility curves, abbreviated by $\mathrm{CPC}_{\mathrm{SE}}^{i}$ for the sequential regime and by $C P C_{S I}^{i}$ for the simultaneous regime, are obtained by eliminating $A_{1}^{i}, A_{2}^{i}$ and $A_{1}^{i}, D_{2}^{i}$, resp., and combining budget equations $(2.1)-(2.3)$, where $D_{2}^{i}=0$ and $A_{2}^{i}=0$, resp.:

$$
C P C_{S E}^{i}: w_{0}-c_{0}^{i}=\widetilde{Q}_{1} c_{1}^{i}+\widetilde{Q}_{2} c_{2}^{i}
$$




$$
C P C_{S I}^{i}: w_{0}-c_{0}^{i}=\bar{Q}_{1} c_{1}^{i}+\bar{R}_{2} c_{2}^{i}
$$

We use the convenient property that in either regime an individual consumes the same amount $c_{0}^{i}$ in the working period to draw the consumption possibilities curves in the $\left(c_{1}^{i}, c_{2}^{i}\right)$ space (see Figure 1 and 2). $C P C_{S E}^{i}$ describes the feasible consumption bundles $\left(c_{1}^{i}, c_{2}^{i}\right)$ for an individual $i$ who invests the fixed amount $w_{0}-c_{0}^{i}=\widetilde{Q}_{1} \tilde{A}_{1}^{i}$ into the first-period contract. She can consume all payouts $c_{1}^{i}=\left(w_{0}-c_{0}^{i}\right) / \widetilde{Q}_{1}$ in period 1 or transform part of it into secondperiod consumption, by buying the sequential second-period contract at price $\widetilde{\mathrm{Q}}_{2}$. If she transforms everything, then $c_{2}^{i}=\left(w_{0}-c_{0}^{i}\right) /\left(\widetilde{Q}_{1} \widetilde{Q}_{2}\right)$ results. On the hand, the $C P C_{S I}^{i}$ represents all feasible consumption bundles for an individual $i$ who invests the same amount $w_{0}-c_{0}^{i}$ (in the working period 0 !) into the $A_{1}$ - and $D_{2}$-contract. Hence, in this regime, the trade-off between consumption in period 1 and in period 2 is $-\bar{Q}_{1} / \bar{R}_{2}$, which is price ratio for one unit payout in the second and in the first retirement period. In either regime, an individual $\mathrm{i}$ chooses $\left(\mathrm{c}_{1}^{i}, \mathrm{c}_{2}^{i}\right)$ by maximizing $\mathrm{u}\left(\mathrm{c}_{1}^{i}\right)+\pi_{2}^{i} \mathrm{u}\left(\mathrm{c}_{2}^{i}\right)$ subject to respective consumption possibility set.

Figure 1

Figure 2
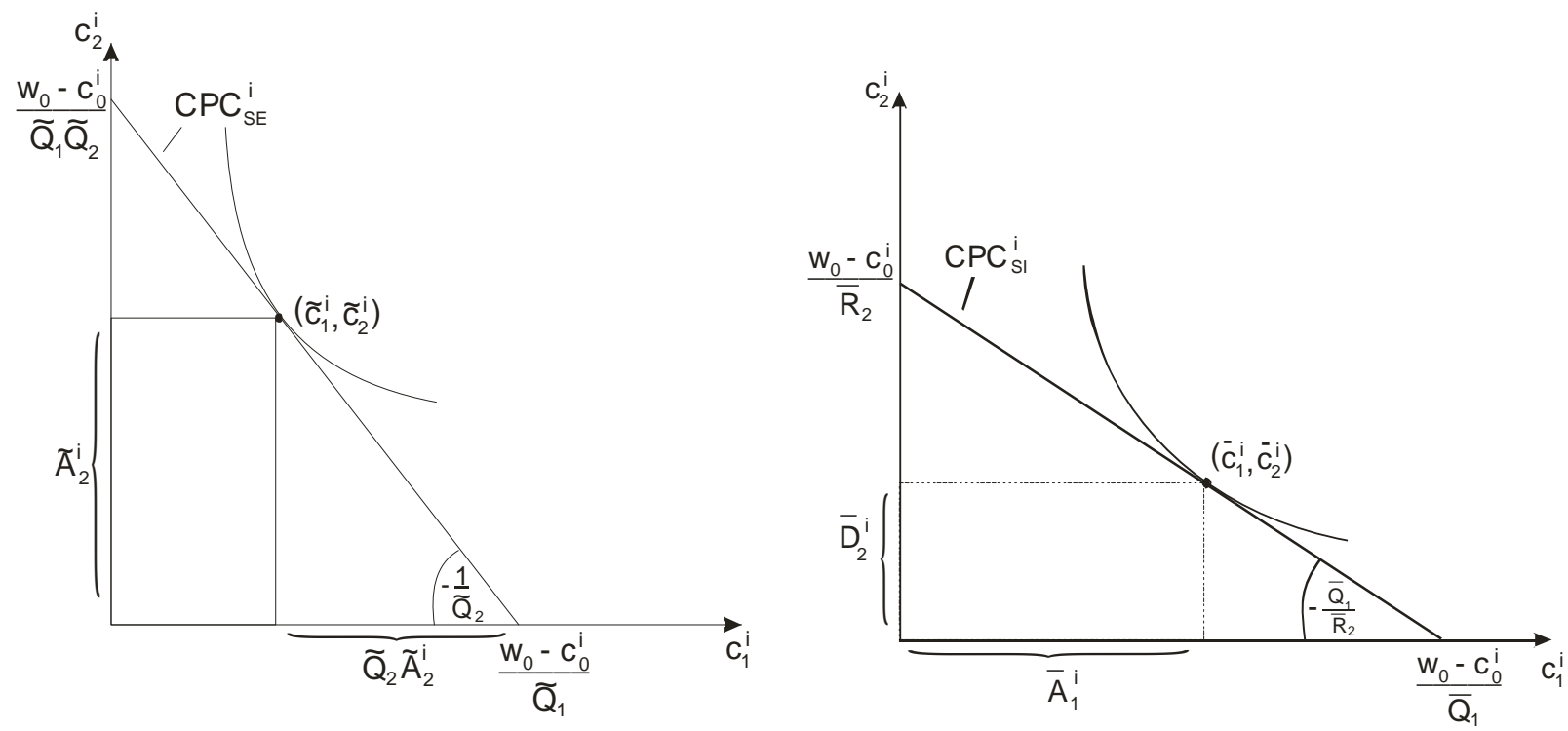

A comparison of the consumption possibility curves in both regimes demonstrates that $\mathrm{CPC}_{\mathrm{SI}}^{\mathrm{i}}$ is flatter than $C P C_{S E}^{i}$, because $\overline{\mathrm{Q}}_{1} \widetilde{\mathrm{Q}}_{2}<\overline{\mathrm{R}}_{2}$ due to Lemma 6 . This inequality is responsible for the fact that relative consumption $c_{2}^{i} / c_{1}^{i}$ is lower in the simultaneous regime than in the sequential regime, as shown in Lemma 7. Further, the curve $\mathrm{CPC}_{\mathrm{SI}}^{\mathrm{i}}$ crosses the $c_{1}^{i}$-axis at a higher level than the curve $C P C_{S E}^{i}$, since $\bar{Q}_{1}<\widetilde{Q}_{1}$. The opposite holds for its 
crossing with the $c_{2}^{i}$-axis, since $\widetilde{Q}_{1} \widetilde{Q}_{2}<\bar{R}_{2}$. It follows that the CPC's intersect and that the sequential regime allows higher consumption to the left of the point of intersection, but lower consumption to the right. This property is essential for following result on welfare:

Proposition 3: An individual of type $L$ is better off in the simultaneous regime with prices $\overline{\mathrm{Q}}_{1}, \overline{\mathrm{R}}_{2}$, while an individual of type $\mathrm{H}$ is better off in the sequential regime with prices $\widetilde{\mathrm{Q}}_{1}, \widetilde{\mathrm{Q}}_{2}$.

Proof: See Appendix.

We give a graphical illustration of Proposition 3 in Figure 3 , where the consumption possibility curves (3.14) and (3.15) of both types of individuals $\mathrm{i}=\mathrm{L}, \mathrm{H}$ are drawn, denoted by $\mathrm{CPC}_{\mathrm{SE}}^{\mathrm{L}}$ and $\mathrm{CPC}_{\mathrm{SI}}^{\mathrm{L}}$ for a low-risk type and by $\mathrm{CPC}_{\mathrm{SE}}^{\mathrm{H}}$ and $\mathrm{CPC}_{\mathrm{SI}}^{\mathrm{H}}$ for a high-risk type. Note that due to adverse selection the long-living individuals make more provision for retirement, therefore their consumption possibility curves are above those of the short-living.

Figure 3

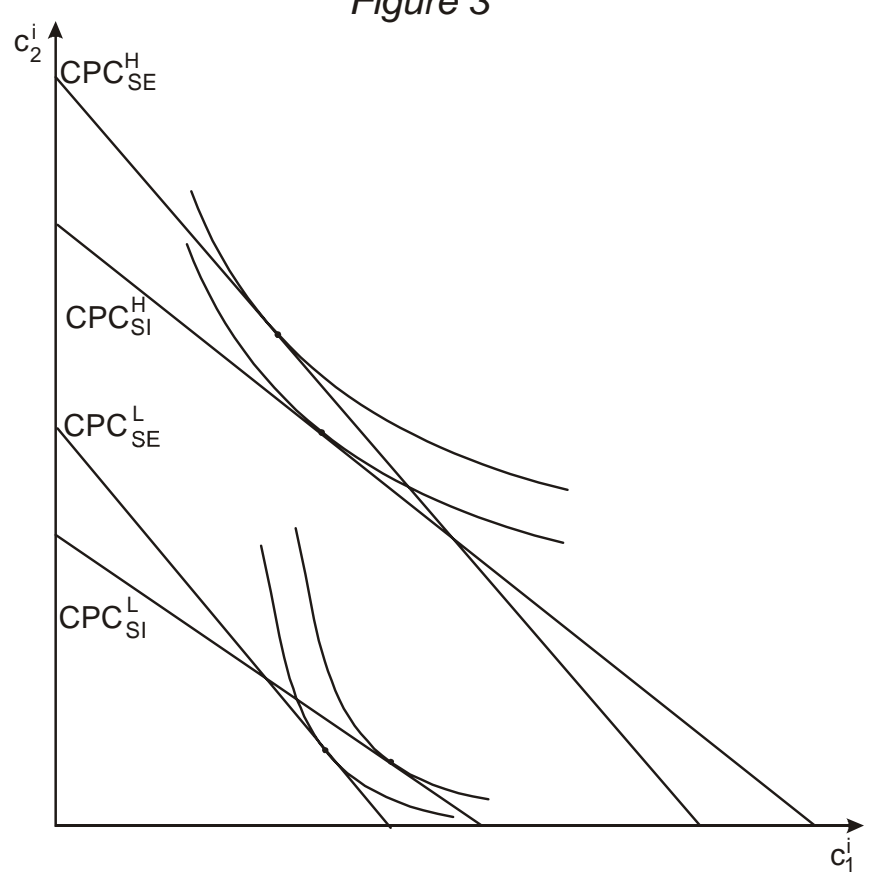

Essential for the result of Proposition 3 is that at any combination $\left(c_{1}^{i}, c_{2}^{i}\right)$ the slope $-c_{2}^{i} /\left(\pi_{2}^{i} c_{1}^{i}\right)$ of the indifference curve is steeper for a type- $L$ individual than for a type-H individual, as $\pi_{2}^{L}<\pi_{2}^{H}$. As one can show, this property implies that, irrespective of the regime, the optimal combination for a type-L individual is to the right of the point of intersection of her consumption possibility curves $\mathrm{CPC}_{\mathrm{SE}}^{\mathrm{L}}$ and $\mathrm{CPC}_{\mathrm{SI}}^{\mathrm{L}}$, while the optimal 
consumption bundle for a type-H individual lies to the left of the intersection of $\mathrm{CPC}_{\mathrm{SE}}^{\mathrm{H}}$ and $\mathrm{CPC}_{\mathrm{SI}}^{\mathrm{H}}$. Consequently, since the simultaneous regime allows higher consumption possibilities to the right of the point of intersection, it is preferred by a type- $L$ individual. The opposite holds for a type-H individual.

This result conforms with the intuition that the short-living individuals, who put more weight on consumption in period one, are indeed better off with that regime which provides more consumption in this period (Lemma 7). Conversely, the long-living individuals are better off with the sequential regime, which provides more consumption in period two.

\section{Concluding Remarks}

Provision for old age can be made through a variety of annuity products, which differ in the terms concerning asset accumulation and the payout path. In the present paper we have concentrated on annuities which run over a limited time only and have to be supplemented by a second contract. This additional contract can either be bought simultaneously with the first or later, when an individual knows that she has survived some years of retirement. We have characterised demand, given these two possibilities, and we have studied the consequences of the adverse-selection phenomenon in this market. The results show that only a situation, where all individuals demand sequential contracts represents an equilibrium. This is favourable for the high-risk group, while the low-risk group would be better off with the simultaneous regime. This result, though derived in a specific framework, shows some similarity to conclusions from other models with asymmetric information, where typically the low-risk groups do not receive their first-best contract.

The main conclusion from our contribution is that adverse selection has more severe consequences on the annuity market than recognised in studies using the standard overlapping-generations model. These mainly concentrate on the influence of adverse selection on a single rate of return for a uniform period of retirement. By extending this model and making the realistic assumption that provision for retirement need not be made through a once-and-for-all annuity contract, but can be made through different contracts for earlier and later phases of retirement, one finds that adverse selection also affects the choice of contracts as well as the existence and properties of equilibria. 
Two important assumptions were used in this study in order to derive the results: logarithmic utility and the possibility of credible commitment. The former one is essentially a technical assumption, allowing us to construct a framework, which is sufficiently simple to derive the definite results in Section 3. Considering the intuition provided below Lemma 6, it appears quite likely that the relations stated in this Lemma hold for a broader class of utility functions. Ultimately, the important relation that drives the final result is $\widetilde{Q}_{1} \widetilde{Q}_{2}<\bar{R}_{2}$, that is, for periodtwo contracts the problem of adverse selection is relieved in the sequential regime, compared to the simultaneous regime. The reason is that in the sequential regime insurance goes via period 1 where the high-risk individuals are in a common pool with the low-risk individuals, who put more weight on the first period of retirement than on the second. Indeed, numerical simulations using an isoleastic per-period utility function have shown that the relation $\widetilde{\mathrm{Q}}_{1} \widetilde{\mathrm{Q}}_{2}<\overline{\mathrm{R}}_{2}$ holds generally for any isoleastic per-period utility function.

On the other hand, the assumption that insurance companies can credibly commit to offer an insurance contract at a fixed price one period later is essential to establish the sequential regime as an equilibrium. Without commitment, one would have to introduce some way of how beliefs concerning the expected price of a future contract are formulated. At fist glance, in such a formulation the occurrence of uncertainty would make future contracts less attractive, and, as a consequence, the sequential regime less likely to represent an equilibrium.

It is well-known that the observed data from the private annuity market reveal puzzling peculiarities. The most frequently mentioned is that people buy considerably less annuity contracts than one would expect, given their higher return compared to that on other forms of wealth (see, e.g., Friedman and Warshawsky, 1990). Another one is the wide-spread use of so-called "years certain" contracts ${ }^{11}$, which is also difficult to explain within a standard model of household decision. Given the result of our analysis that using time-limited contracts in the sequential regime represents an equilibrium, the observed fact, mentioned in the introduction, that time-limited contracts make up only a small share of all actually purchased annuities adds another puzzle: in fact the majority of individuals buy life annuities for the whole period of retirement altogether, which can be interpreted as the simultaneous regime in our model. A possible explanation could be seen in the lack of commitment as discussed

11 These contracts offer guaranteed for a fixed number periods (possibly to descendants), and then regular payouts until death. Obviously, their price is higher than that of annuities without a guaranteed payout phase. 
above. A further crucial issue of our analysis is the range of annuity contracts or their combinations available to the individuals. Further research is needed in order to clarify the functioning of the market, if additional types of contracts, for instance packages of first- and second-period insurance, are introduced.

\section{Appendix}

\section{Proof of Lemma 1:}

By use of the equations in (2.8a), (2.9) and (2.10), equation (2.6) can be written as $-\mathrm{Q}_{1} \mathrm{Q}_{2} \mathrm{u}^{\prime}\left(\mathrm{w}_{0}-\mathrm{Q}_{1} \mathrm{~A}_{1}^{\mathrm{i}}-\mathrm{R}_{2} \mathrm{D}_{2}^{\mathrm{i}}\right)+\pi_{1}^{\mathrm{i}} \partial \varphi^{\mathrm{i}}\left(\mathrm{A}_{1}^{\mathrm{i}}, \mathrm{Q}_{2}, \mathrm{D}_{2}^{\mathrm{i}}\right) / \partial \mathrm{D}_{2}^{\mathrm{i}}=0$, where the first term on the LHS in general will not be equal to the term $-R_{2} u^{\prime}\left(w_{0}-Q_{1} A_{1}^{i}-R_{2} D_{2}^{i}\right)$ of the equation in (2.7a). As we know that (2.6) must always be fulfilled, this means that the equations in (2.7a) and (2.8a) cannot hold simultaneously. By the same reasoning, one observes that if (2.8a) holds, (2.7b) can be fulfilled only if $R_{2} \geq Q_{1} Q_{2}$, and analogously for (2.7a) and (2.8b).

Q.E.D.

\section{Proof of Lemma 2:}

Part (i): We denote by $\mathrm{W}^{i}$ the LHS of (2.6) and by $\mathrm{V}^{\mathrm{i}}$ the LHS of the equation in (2.8a), where $\mathrm{D}_{2}^{\mathrm{i}}=0$. Implicit differentiation gives

$$
\left(\begin{array}{ll}
\frac{\partial A_{1}^{i}}{\partial Q_{1}} & \frac{\partial A_{1}^{i}}{\partial Q_{2}} \\
\frac{\partial A_{2}^{i}}{\partial Q_{1}} & \frac{\partial A_{2}^{i}}{\partial Q_{2}}
\end{array}\right)=-\left(\begin{array}{ll}
\frac{\partial W^{i}}{\partial A_{1}^{i}} & \frac{\partial W^{i}}{\partial A_{2}^{i}} \\
\frac{\partial V^{i}}{\partial A_{1}^{i}} & \frac{\partial V^{i}}{\partial A_{2}^{i}}
\end{array}\right)^{-1}\left(\begin{array}{ll}
\frac{\partial W^{i}}{\partial Q_{1}} & \frac{\partial W^{i}}{\partial Q_{2}} \\
\frac{\partial V^{i}}{\partial Q_{1}} & \frac{\partial V^{i}}{\partial Q_{2}}
\end{array}\right) .
$$

We find that

$$
\begin{aligned}
& \frac{\partial V^{i}}{\partial A_{1}^{i}}=-Q_{2} u^{\prime \prime}\left(c_{1}^{i}\right)>0, \\
& \frac{\partial \mathrm{V}^{\mathrm{i}}}{\partial \mathrm{A}_{2}^{\mathrm{i}}}=\mathrm{Q}_{2}^{2} \mathrm{u}^{\prime \prime}\left(\mathrm{c}_{1}^{\mathrm{i}}\right)+\pi_{2}^{\mathrm{i}} \mathrm{u}^{\prime \prime}\left(\mathrm{c}_{2}^{\mathrm{i}}\right)<0 \text {, } \\
& \frac{\partial W^{i}}{\partial A_{1}^{i}}=Q_{1}^{2} u^{\prime \prime}\left(c_{0}^{i}\right)+\pi_{1}^{i} \frac{\partial^{2} \varphi\left(A_{1}^{i}, Q_{2}\right)}{\partial w_{1}^{i} 2}=Q_{1}^{2} u^{\prime \prime}\left(c_{0}^{i}\right)+\pi_{1}^{i}\left(1-Q_{2} \frac{\partial A_{2}^{i}\left(A_{1}^{i}, Q_{2}\right)}{\partial A_{1}^{i}}\right) .
\end{aligned}
$$

due to (2.9), where $A_{2}^{i}\left(A_{1}^{i}, Q_{2}\right)$ denotes annuity demand $A_{2}^{i}$ for fixed $A_{1}^{i}=A_{1}^{i}$, determined by (2.8a). Hence, $\partial A_{2}^{i}\left(A_{1}^{i}, Q_{2}\right) / \partial A_{1}^{i}$ is derived from implicit differentiation of (2.8a) as 


$$
\frac{\partial A_{2}^{i}}{\partial A_{1}^{i}}=\frac{Q_{2} u^{\prime \prime}\left(C_{1}^{i}\right)}{\partial V^{i} / \partial A_{2}^{i}}
$$

By use of (A3) - (A5) we obtain

$$
\frac{\partial W^{i}}{\partial A_{1}^{i}}=Q_{1}^{2} u^{\prime \prime}\left(c_{0}^{i}\right)+\pi_{1}^{i} \pi_{2}^{i} \frac{u^{\prime \prime}\left(c_{1}^{i}\right) u^{\prime \prime}\left(A_{2}^{i}\right)}{\partial V^{i} / \partial A_{2}^{i}}<0 .
$$

Further, we have:

$$
\begin{aligned}
& \frac{\partial W^{i}}{\partial A_{2}^{i}}=0, \\
& \frac{\partial V^{i}}{\partial Q_{1}}=0, \\
& \frac{\partial V^{i}}{\partial Q_{2}}=-u^{\prime}\left(c_{1}^{i}\right)+Q_{2} A_{2}^{i} u^{\prime \prime}\left(c_{1}^{i}\right)<0, \\
& \frac{\partial W^{i}}{\partial Q_{1}}=-u^{\prime}\left(c_{0}^{i}\right)+Q_{1} A_{1}^{i} u^{\prime \prime}\left(c_{0}^{i}\right)<0, \\
& \frac{\partial W^{i}}{\partial Q_{2}}=\pi_{1}^{i} \frac{\partial^{2} \varphi^{i}\left(A_{1}^{i}, Q_{2}\right)}{\partial A_{1}^{i} \partial Q_{2}}=-\pi_{1}^{i} u^{\prime \prime}\left(c_{1}^{i}\right)\left(A_{2}^{i}+Q_{2} \frac{\partial A_{2}^{i}\left(A_{1}^{i}, Q_{2}\right)}{\partial Q_{2}}\right),
\end{aligned}
$$

due to (2.9). By use of $\varepsilon_{2}^{i}\left(A_{1}^{i}, Q_{2}\right) \equiv \frac{\partial A_{2}^{i}\left(A_{1}^{i}, Q_{2}\right)}{\partial Q_{2}} \frac{Q_{2}}{A_{2}^{i}}$, denoting the price elasticity of demand $A_{2}^{i}\left(A_{1}^{i}, Q_{2}\right)$ for fixed $w_{1}^{i}$, together with (differentiate (2.8a) implicitly and use (A2) and (A3))

$$
\frac{\partial \mathrm{A}_{2}^{\mathrm{i}}\left(\mathrm{A}_{1}^{\mathrm{i}}, \mathrm{Q}_{2}\right)}{\partial \mathrm{Q}_{2}}=-\frac{\partial \mathrm{V}^{\mathrm{i}} / \partial \mathrm{Q}_{2}}{\partial \mathrm{V}^{\mathrm{i}} / \partial \mathrm{A}_{2}^{\mathrm{i}}}<0,
$$

we obtain

$$
\frac{\partial W^{i}}{\partial Q_{2}}=-\pi_{1}^{i} A_{2}^{i} u^{\prime \prime}\left(c_{1}^{i}\right)\left(1+\varepsilon_{2}^{i}\left(A_{1}^{i}, Q_{2}\right)\right) \gtreqless 0 \Leftrightarrow \varepsilon_{2}^{i}\left(A_{1}^{i}, Q_{2}\right) \gtreqless-1, \varepsilon_{2}^{i}\left(A_{1}^{i}, Q_{2}\right)<0 .
$$

Now let

$$
N \equiv \underbrace{\frac{\partial W^{i}}{\partial A_{1}^{i}}}_{<0} \frac{\partial V^{i}}{\frac{\partial A_{2}^{i}}{s_{2}}}-\underbrace{\frac{\partial W^{i}}{\partial A_{2}^{i}} \frac{\partial V^{i}}{\partial A_{1}^{i}}}_{=0}>0 .
$$

Inverting the first matrix on the RHS of (A1) and multiplying gives (note the inequalities from above):

$$
\frac{\partial A_{1}^{i}\left(Q_{1}, Q_{2}\right)}{\partial Q_{1}}=-\frac{1}{N}(\underbrace{\frac{\partial V^{i}}{\partial A_{2}^{i}}}_{<0} \underbrace{\frac{\partial W^{i}}{\partial Q_{1}}}_{<0}-\underbrace{\frac{\partial W^{i}}{\partial A_{2}^{i}} \frac{\partial V^{i}}{\partial Q_{1}}}_{=0})<0,
$$




$$
\begin{aligned}
& \frac{\partial A_{2}^{i}\left(Q_{1}, Q_{2}\right)}{\partial Q_{1}}=-\frac{1}{N}(-\underbrace{\frac{\partial V^{i}}{\partial A_{1}^{i}}}_{>0} \underbrace{\frac{\partial W^{i}}{\partial Q_{1}}}_{<0}+\underbrace{\frac{\partial W^{i}}{\partial A_{1}^{i}} \frac{\partial V^{i}}{\partial Q_{1}}}_{=0})<0, \\
& \frac{\partial A_{1}^{i}\left(Q_{1}, Q_{2}\right)}{\partial Q_{2}}=-\frac{1}{N}(\underbrace{\frac{\partial V^{i}}{\partial A_{2}^{i}} \frac{\partial W^{i}}{\partial Q_{2}}}_{<0}-\underbrace{\left.\frac{\partial W^{i}}{\partial A_{2}^{i} \frac{\partial V^{i}}{\partial Q_{2}}}\right) \gtreqless 0 \Leftrightarrow \varepsilon_{2}^{i}\left(A_{1}^{i}, Q_{2}\right) \gtreqless-1,}_{=0} \\
& \frac{\partial A_{2}^{i}\left(Q_{1}, Q_{2}\right)}{\partial Q_{2}}=-\frac{1}{N}(-\underbrace{\frac{\partial V^{i}}{\partial A_{1}^{i}}}_{>0} \frac{\partial W^{i}}{\partial Q_{2}}+\underbrace{\frac{\partial W^{i}}{\partial A_{1}^{i}} \underbrace{\frac{\partial Q_{2}^{i}}{\partial Q_{2}}}_{<0}}_{<0}),
\end{aligned}
$$

which can rearranged to [use (A2), (A6), (A9), (A11) and (A12)]

$$
\begin{aligned}
\frac{\partial A_{2}^{i}\left(Q_{1}, Q_{2}\right)}{\partial Q_{2}} & =-\frac{1}{N}\left[Q_{2} u^{\prime \prime}\left(c_{1}^{i}\right)\left(\frac{\partial W^{i}}{\partial Q_{2}}+A_{2}^{i} \frac{\partial W^{i}}{\partial A_{1}^{i}}\right)-\frac{\partial W^{i}}{\partial A_{1}^{i}} u^{\prime}\left(c_{1}^{i}\right)\right] \\
& =-\frac{1}{N}\left[Q_{2} u^{\prime \prime}\left(c_{1}^{i}\right)\left(-\frac{\pi_{1}^{i} Q_{2} u^{\prime \prime}\left(c_{1}^{i}\right) u^{\prime}\left(c_{1}^{i}\right)}{\partial V^{i} / \partial A_{2}^{i}}+Q_{1}^{2} A_{2}^{i} u^{\prime \prime}\left(c_{0}^{i}\right)\right)-\frac{\partial W^{i}}{\partial A_{1}^{i}} u^{\prime}\left(c_{1}^{i}\right)\right]<0 .
\end{aligned}
$$

Part (ii): Let now denote $W^{i}$ and $V^{i}$ the LHS's of (2.6) and (2.7a), resp. With $A_{2}^{i}=0$ these equations reduce to (see (2.9), (2.10))

$$
\begin{aligned}
& -Q_{1} u^{\prime}\left(w_{0}-Q_{1} A_{1}^{i}-R_{2} D_{2}^{i}\right)+\pi_{1}^{i} u^{\prime}\left(A_{1}^{i}\right)=0, \\
& -R_{2} u^{\prime}\left(w_{0}-Q_{1} A_{1}^{i}-R_{2} D_{2}^{i}\right)+\pi_{1}^{i} \pi_{2}^{i} u^{\prime}\left(D_{2}^{i}\right)=0 .
\end{aligned}
$$

The formula for implicit differentiation of these equations is the same as (A1), when $A_{2}^{i}$ is replaced by $\mathrm{D}_{2}^{\mathrm{i}}$ and $\mathrm{Q}_{2}$ by $\mathrm{R}_{2}$.

We find that

$$
\begin{array}{ll}
\frac{\partial W^{i}}{\partial A_{1}^{i}}=Q_{1}^{2} u^{\prime \prime}\left(c_{0}^{i}\right)+\pi_{1}^{i} u^{\prime \prime}\left(c_{1}^{i}\right)<0, & \frac{\partial W^{i}}{\partial D_{2}^{i}}=Q_{1} R_{2} u^{\prime \prime}\left(c_{0}^{i}\right)<0, \\
\frac{\partial V^{i}}{\partial A_{1}^{i}}=Q_{1} R_{2} u^{\prime \prime}\left(c_{0}^{i}\right)<0, & \frac{\partial V^{i}}{\partial D_{2}^{i}}=R_{2}^{2} u^{\prime \prime}\left(c_{0}^{i}\right)+\pi_{1}^{i} \pi_{2}^{i} u^{\prime \prime}\left(c_{2}^{i}\right)<0, \\
\frac{\partial W^{i}}{\partial Q_{1}}=-u^{\prime}\left(c_{0}^{i}\right)+Q_{1} A_{1}^{i} u^{\prime \prime}\left(c_{0}^{i}\right)<0, & \frac{\partial W^{i}}{\partial R_{2}}=Q_{1} D_{2} u^{\prime \prime}\left(c_{0}^{i}\right)<0, \\
\frac{\partial V^{i}}{\partial Q_{1}}=R_{2} A_{1}^{i} u^{\prime \prime}\left(c_{0}^{i}\right)<0, & \frac{\partial V^{i}}{\partial R_{2}}=-u^{\prime}\left(c_{0}^{i}\right)+R_{2} D_{2}^{i} u^{\prime \prime}\left(c_{0}^{i}\right)<0 .
\end{array}
$$

Now let

$$
M \equiv \frac{\partial W^{i}}{\partial A_{1}^{i}} \frac{\partial V^{i}}{\partial D_{2}^{i}}-\frac{\partial W^{i}}{\partial D_{2}^{i}} \frac{\partial V^{i}}{\partial A_{1}^{i}}>0
$$


where the positive sign follows immediately from easy calculation by use of (A21) and (A23). One derives immediately, using (A15) - (A19), together with (A22) - (A26) and by some straightforward computations:

$$
\begin{aligned}
& \frac{\partial A_{1}^{i}\left(Q_{1}, R_{2}\right)}{\partial Q_{1}}=-\frac{1}{M}\left(\frac{\partial V^{i}}{\partial D_{2}^{i}} \frac{\partial W^{i}}{\partial Q_{1}}-\frac{\partial W^{i}}{\partial D_{2}^{i}} \frac{\partial V^{i}}{\partial Q_{1}}\right)<0, \\
& \frac{\partial D_{2}^{i}\left(Q_{1}, R_{2}\right)}{\partial R_{2}}=-\frac{1}{M}\left(-\frac{\partial V^{i}}{\partial A_{1}^{i}} \frac{\partial W^{i}}{\partial R_{2}}+\frac{\partial W^{i}}{\partial A_{1}^{i}} \frac{\partial V^{i}}{\partial R_{2}}\right)<0 .
\end{aligned}
$$

Further, we find that

$$
\frac{\partial D_{2}^{i}\left(Q_{1}, R_{2}\right)}{\partial Q_{1}}=-\frac{1}{M}\left(-\frac{\partial V^{i}}{\partial A_{1}^{i}} \frac{\partial W^{i}}{\partial Q_{1}}+\frac{\partial W^{i}}{\partial A_{1}^{i}} \frac{\partial V^{i}}{\partial Q_{1}}\right)=-\frac{1}{M} R_{2} u^{\prime \prime}\left(c_{0}^{i}\right)\left(-Q_{1} \frac{\partial W^{i}}{\partial Q_{1}}+A_{1}^{i} \frac{\partial W^{i}}{\partial A_{1}^{i}}\right) .
$$

Substituting the price elasticity of demand $A_{1}^{i}\left(D_{2}^{i}, Q_{1}\right)$ for fixed $D_{2}^{i}$, defined as $\eta_{1}^{i} \equiv \frac{\partial A_{1}^{i}\left(D_{2}^{i}, Q_{1}\right)}{\partial Q_{1}} \frac{Q_{1}}{A_{1}^{i}}$, together with $\frac{\partial A_{1}^{i}\left(D_{2}^{i}, Q_{1}\right)}{\partial Q_{1}}=-\frac{\partial W^{i} / \partial Q_{1}}{\partial W^{i} / \partial A_{1}^{i}}<0$ (differentiate (A20) implicitly) into (A29) yields

$$
\frac{\partial D_{2}^{i}\left(Q_{1}, R_{2}\right)}{\partial Q_{1}}=-\frac{1}{M} R_{2} u^{\prime \prime}\left(c_{0}^{i}\right) A_{1}^{i} \frac{\partial W^{i}}{\partial A_{1}^{i}}\left(\eta_{1}+1\right) \gtreqless 0 \Leftrightarrow \eta_{1}^{i} \lesseqgtr-1, \eta_{1}^{i}<0 .
$$

Analogously, we use the price elasticity $\eta_{2}^{i} \equiv \frac{\partial D_{2}^{i}\left(A_{1}^{i}, R_{2}\right)}{\partial R_{2}} \frac{R_{2}}{D_{2}^{i}}$ of demand $D_{2}^{i}\left(A_{1}^{i}, R_{2}\right)$ for fixed $A_{1}^{i}$, together with $\frac{\partial D_{2}^{i}\left(A_{1}^{i}, R_{2}\right)}{\partial R_{2}}=-\frac{\partial V^{i} / \partial R_{2}}{\partial V^{i} / \partial D_{2}^{i}}<0$ (differentiate (A21) implicitly) to determine the sign of $\partial A_{1}^{i}\left(Q_{1}, R_{2}\right) / \partial R_{2}$ :

$$
\begin{aligned}
\frac{\partial A_{1}^{i}\left(Q_{1}, R_{2}\right)}{\partial R_{2}} & =-\frac{1}{M}\left(\frac{\partial V^{i}}{\partial D_{2}^{i}} \frac{\partial W^{i}}{\partial R_{2}}-\frac{\partial W^{i}}{\partial D_{2}^{i}} \frac{\partial V^{i}}{\partial R_{2}}\right) \\
& =-\frac{1}{M} Q_{1} u^{\prime \prime}\left(c_{0}^{i}\right)\left(D_{2}^{i} \frac{\partial V^{i}}{\partial D_{2}^{i}}-R_{2} \frac{\partial V^{i}}{\partial R_{2}}\right) \\
& =-\frac{1}{M} Q_{1} u^{\prime \prime}\left(c_{0}^{i}\right) D_{2}^{i} \frac{\partial V^{i}}{\partial D_{2}^{i}}\left(1+\eta_{2}^{i}\right) \quad \gtreqless 0 \Leftrightarrow \eta_{2}^{i} \leq-1, \eta_{2}^{i}<0 .
\end{aligned}
$$

Q.E.D.

\section{Proof of Lemma 3:}

Part (i): We define $W^{i}$ and $V^{i}$ as in the proof of Lemma 2, part (i). The formula for implicit differentiation of (2.6) and the equation in (2.8a) is the same as in (A1), where $Q_{1}, Q_{2}$ are replaced by $\pi_{1}^{\mathrm{i}}, \pi_{2}^{\mathrm{i}}$, resp. 
We find that

$$
\begin{aligned}
& \frac{\partial W^{i}}{\partial \pi_{1}^{i}}=\frac{\partial \varphi}{\partial w_{1}^{i}}>0, \\
& \frac{\partial W^{i}}{\partial \pi_{2}^{i}}=\pi_{1}^{i} \frac{\partial^{2} \varphi^{i}\left(w_{1}^{i}, Q_{2}\right)}{\partial w_{1}^{i} \partial \pi_{2}^{i}}=-\pi_{1}^{i} Q_{2} u^{\prime \prime}\left(c_{1}^{i}\right) \frac{\partial A_{2}^{i}\left(w_{1}^{i}, Q_{2}\right)}{\partial \pi_{2}}=\frac{\pi_{1}^{i} Q_{2} u^{\prime \prime}\left(c_{1}^{i}\right) u^{\prime}\left(c_{2}^{i}\right)}{Q_{2}^{2} u^{\prime \prime}\left(c_{1}^{i}\right)+\pi_{2} u^{\prime \prime}\left(c_{2}^{i}\right)}>0,
\end{aligned}
$$

due to (2.9), where $\partial A_{2}^{i}\left(w_{1}^{i}, Q_{2}\right) / \partial \pi_{2}$ (denoting the change of annuity demand for fixed $w_{1}^{i}$, if $\pi_{2}^{\mathrm{i}}$ increases), is determined by implicit differentiation of the equation in (2.8a).

Furthermore:

$$
\frac{\partial V^{i}}{\partial \pi_{1}^{i}}=0, \quad \frac{\partial V^{i}}{\partial \pi_{2}^{i}}=u^{\prime}\left(c_{2}^{i}\right)>0 .
$$

Using these computations (A31) - (A33), together with (A2), (A3), (A6), (A7) and (A14) in (A15) - (A18) gives

$$
\begin{aligned}
& \frac{\partial A_{1}^{i}\left(Q_{1}, Q_{2}\right)}{\partial \pi_{1}^{i}}=-\frac{1}{N} \frac{\partial V^{i}}{\partial A_{2}^{i}} \frac{\partial W^{i}}{\partial \pi_{1}^{i}}>0, \quad \frac{\partial A_{2}^{i}\left(Q_{1}, Q_{2}\right)}{\partial \pi_{1}^{i}}=\frac{1}{N} \frac{\partial V^{i}}{\partial A_{1}^{i}} \frac{\partial W^{i}}{\partial \pi_{1}^{i}}>0, \\
& \frac{\partial A_{1}^{i}\left(Q_{1}, Q_{2}\right)}{\partial \pi_{2}^{i}}=-\frac{1}{N} \frac{\partial V^{i}}{\partial A_{2}^{i}} \frac{\partial W^{i}}{\partial \pi_{2}^{i}}>0, \quad \frac{\partial A_{2}^{i}\left(Q_{1}, Q_{2}\right)}{\partial \pi_{2}^{i}}=-\frac{1}{N}\left(-\frac{\partial V^{i}}{\partial A_{1}^{i}} \frac{\partial W^{i}}{\partial \pi_{2}^{i}}+\frac{\partial W^{i}}{\partial A_{1}^{i}} \frac{\partial V^{i}}{\partial \pi_{2}^{i}}\right)>0 .
\end{aligned}
$$

Part (ii): We define $\mathrm{W}^{i}$ and $\mathrm{V}^{\mathrm{i}}$ as in part (ii) of Lemma 2 and use the same formula (A1) for implicit differentiation of (A20), (A21), where $A_{2}^{i}, Q_{1}, Q_{2}$ are replaced by $D_{2}^{i}, \pi_{1}^{i}, \pi_{2}^{i}$ resp.

We find that

$$
\begin{array}{ll}
\frac{\partial W^{i}}{\partial \pi_{1}^{i}}=u^{\prime}\left(c_{1}^{i}\right)>0, & \frac{\partial W^{i}}{\partial \pi_{2}^{i}}=0, \\
\frac{\partial V^{i}}{\partial \pi_{1}^{i}}=\pi_{2} u^{\prime}\left(c_{2}^{i}\right)>0, & \frac{\partial V^{i}}{\partial \pi_{2}^{i}}=\pi_{1}^{i} u^{\prime}\left(c_{2}^{i}\right)>0 .
\end{array}
$$

Using these computations (A34) and (A35), together with (A22), (A24) and (A26), in (A27) (A30), it follows [note that $R_{2} u^{\prime}\left(c_{1}^{i}\right)=\pi_{2}^{i} Q_{1} u^{\prime}\left(c_{2}^{i}\right)$ due to $(A 20)$ and $(A 21)$ ]:

$$
\begin{aligned}
& \frac{\partial A_{1}^{i}\left(Q_{1}, R_{2}\right)}{\partial \pi_{1}^{i}}=-\frac{1}{M}\left(\frac{\partial V^{i}}{\partial D_{2}^{i}} \frac{\partial W^{i}}{\partial \pi_{1}^{i}}-\frac{\partial W^{i}}{\partial D_{2}^{i}} \frac{\partial V^{i}}{\partial \pi_{1}^{i}}\right)=-\frac{1}{M} \pi_{1}^{i} \pi_{2}^{i} u^{\prime \prime}\left(c_{0}^{i}\right) u^{\prime}\left(c_{1}^{i}\right)>0, \\
& \frac{\partial D_{2}^{i}\left(q_{1}, r_{2}\right)}{\partial \pi_{1}^{i}}=-\frac{1}{M}\left(-\frac{\partial V^{i}}{\partial A_{1}^{i}} \frac{\partial W^{i}}{\partial \pi_{1}^{i}}+\frac{\partial W^{i}}{\partial A_{1}^{i}} \frac{\partial V^{i}}{\partial \pi_{1}^{i}}\right)=-\frac{1}{M} \pi_{1}^{i} u^{\prime \prime}\left(c_{1}^{i}\right) \pi_{2}^{i} u^{\prime}\left(c_{2}^{i}\right)>0,
\end{aligned}
$$




$$
\begin{aligned}
& \frac{\partial A_{1}^{i}\left(Q_{1}, R_{2}\right)}{\partial \pi_{2}^{i}}=\frac{1}{M} \frac{\partial W^{i}}{\partial D_{2}^{i}} \frac{\partial V^{i}}{\partial \pi_{2}^{i}}<0, \\
& \frac{\partial D_{1}^{i}\left(Q_{1}, R_{2}\right)}{\partial \pi_{2}^{i}}=-\frac{1}{M} \frac{\partial W^{i}}{\partial A_{1}^{i}} \frac{\partial V^{i}}{\partial \pi_{2}^{i}}>0 .
\end{aligned}
$$

Q.E.D.

\section{Proof of Lemma 6:}

(i) By use of the first equation in (3.8), (3.10), (3.11) and (3.13), $\widetilde{\rho}_{1}$ can be written as

$$
\tilde{\rho}_{1}=\frac{\left(1+\pi_{2}^{\mathrm{H}}\right)}{\left(1+\pi_{2}^{\mathrm{L}}\right)} \bar{\rho}_{1},
$$

which is larger than $\bar{\rho}_{1}$, as $\pi_{2}^{\mathrm{H}}>\pi_{2}^{\mathrm{L}}$. By use of (3.4) and the second equation in (3.8), (3.10), (3.11) and (3.13), $\tilde{\rho}_{2}$ can be written as

$$
\tilde{\rho}_{2}=\frac{\pi_{1}^{\mathrm{H}}}{\pi_{1}^{\mathrm{L}}} \bar{\rho}_{2},
$$

which is larger than $\bar{\rho}_{2}$, as $\pi_{1}^{\mathrm{H}}>\pi_{1}^{\mathrm{L}}$. By use of the first equation in (3.8) and (3.10) and the second equation in (3.11) and (3.13) $\tilde{\rho}_{1}$ can be written as

$$
\tilde{\rho}_{1}=\frac{\bar{\rho}_{2}\left(\pi_{2}^{\mathrm{L}}+\pi_{2}^{\mathrm{H}} \pi_{2}^{\mathrm{L}}\right)}{\left(\pi_{2}^{\mathrm{H}}+\pi_{2}^{\mathrm{L}} \pi_{2}^{\mathrm{H}}\right)},
$$

which is smaller than $\bar{\rho}_{2}$, as $\pi_{2}^{H}>\pi_{2}^{\mathrm{L}}$.

(ii) First, we calculate the difference $\left(\widetilde{\mathrm{Q}}_{1}-\overline{\mathrm{Q}}_{1}\right)$ from the first equations in (3.9) and (3.12) as

$$
\widetilde{\mathrm{Q}}_{1}-\overline{\mathrm{Q}}_{1}=\frac{\left(\pi_{1}^{\mathrm{H}}-\pi_{1}^{\mathrm{L}}\right)\left(\tilde{\rho}_{1}-\bar{\rho}_{1}\right)}{\left(1+\tilde{\rho}_{1}\right)\left(1+\bar{\rho}_{1}\right)},
$$

which is positive due to $\tilde{\rho}_{1}>\bar{\rho}_{1}$ and $\pi_{1}^{\mathrm{H}}>\pi_{1}^{\mathrm{L}}$.

Next, we show that $\widetilde{Q}_{2}>\bar{R}_{2}$ : Using the second equations in (3.9), (3.12) and (A37), the price ratio $\bar{R}_{2} / \widetilde{Q}_{2}$ can be written as

$$
\frac{\overline{\mathrm{R}}_{2}}{\widetilde{\mathrm{Q}}_{2}}=\frac{\pi_{1}^{\mathrm{L}}+\pi_{1}^{\mathrm{H}} \bar{\rho}_{2}}{1+\bar{\rho}_{2}},
$$

which is smaller than 1 due to $\pi_{1}^{i}<1$, for $i=L, H$. 
Finally, we show that $\widetilde{\mathrm{Q}}_{1} \widetilde{\mathrm{Q}}_{2}<\overline{\mathrm{R}}_{2}$, which is equivalent to $\widetilde{\mathrm{Q}}_{1}-\overline{\mathrm{R}}_{2} / \widetilde{\mathrm{Q}}_{2}<0$. Substituting the first equation of (3.9) and (A40) into the difference $\widetilde{Q}_{1}-\bar{R}_{2} / \widetilde{Q}_{2}$ yields (after some easy steps of calculations)

$$
\widetilde{\mathrm{Q}}_{1}-\frac{\overline{\mathrm{R}}_{2}}{\widetilde{\mathrm{Q}}_{2}}=\frac{\left(\pi_{1}^{\mathrm{H}}-\pi_{1}^{\mathrm{L}}\right)\left(\tilde{\rho}_{1}-\bar{\rho}_{2}\right)}{\left(1+\bar{\rho}_{2}\right)\left(1+\tilde{\rho}_{1}\right)},
$$

which is negative, since $\pi_{1}^{\mathrm{H}}>\pi_{1}^{\mathrm{L}}$ and $\bar{\rho}_{2}>\tilde{\rho}_{1}$.

Q.E.D.

\section{Proof of Lemma 7:}

(i) This result follows from the fact that $Q_{1} \tilde{A}_{1}^{i}=Q_{1} \bar{A}_{1}^{i}+R_{2} \bar{D}_{2}^{i}$ : substituting the first equation in (3.8) and $D_{2}^{i}=0$ into (2.1) gives the same consumption level $c_{0}^{i}$ as substituting the both equations in (3.13) into (2.1).

(ii) Substituting both equations in (3.8) into (2.2) as well as the first equation in (3.11) and $A_{2}^{i}=0$ into (2.2) gives

$$
\begin{aligned}
& \mathrm{c}_{1}^{\mathrm{i}}\left(\widetilde{\mathrm{Q}}_{1}, \widetilde{\mathrm{Q}}_{2}\right)=\tilde{\mathrm{A}}_{1}^{\mathrm{i}}\left(\widetilde{\mathrm{Q}}_{1}, \widetilde{\mathrm{Q}}_{2}\right)-\widetilde{\mathrm{Q}}_{2} \tilde{\mathrm{A}}_{2}^{\mathrm{i}}\left(\widetilde{\mathrm{Q}}_{1}, \widetilde{\mathrm{Q}}_{2}\right)=\mathrm{X}_{\mathrm{i}} / \widetilde{\mathrm{Q}}_{1} ; \\
& \mathrm{c}_{1}^{\mathrm{i}}\left(\overline{\mathrm{Q}}_{1}, \overline{\mathrm{R}}_{2}\right)=\overline{\mathrm{A}}_{1}^{\mathrm{i}}\left(\overline{\mathrm{Q}}_{1}, \overline{\mathrm{R}}_{2}\right)=\mathrm{X}_{\mathrm{i}} / \overline{\mathrm{Q}}_{1} .
\end{aligned}
$$

Due to Lemma 6 (ii), $\widetilde{\mathrm{Q}}_{1}>\overline{\mathrm{Q}}_{1}$, and it follows that $\mathrm{c}_{1}^{\mathrm{i}}\left(\widetilde{\mathrm{Q}}_{1}, \widetilde{\mathrm{Q}}_{2}\right)<\mathrm{c}_{1}^{\mathrm{i}}\left(\overline{\mathrm{Q}}_{1}, \overline{\mathrm{R}}_{2}\right)$.

(iii) Substituting the second equation in (3.7) and $D_{2}^{i}=0$ into (2.3) as well as (3.14) and $A_{2}^{i}=0$ into (2.3) yields

$$
\begin{aligned}
& \mathrm{c}_{2}^{\mathrm{i}}\left(\widetilde{\mathrm{Q}}_{1}, \widetilde{\mathrm{Q}}_{2}\right)=\tilde{\mathrm{A}}_{2}^{\mathrm{i}}\left(\widetilde{\mathrm{Q}}_{1}, \widetilde{\mathrm{Q}}_{2}\right)=\pi_{2}^{\mathrm{i}} \mathrm{X}_{\mathrm{i}} /\left(\widetilde{\mathrm{Q}}_{1} \widetilde{\mathrm{Q}}_{2}\right) ; \\
& \mathrm{c}_{2}^{\mathrm{i}}\left(\overline{\mathrm{Q}}_{1}, \overline{\mathrm{R}}_{2}\right)=\overline{\mathrm{D}}_{2}^{\mathrm{i}}\left(\overline{\mathrm{Q}}_{1}, \overline{\mathrm{R}}_{2}\right)=\pi_{2}^{\mathrm{i}} \mathrm{X}_{\mathrm{i}} / \overline{\mathrm{R}}_{2} .
\end{aligned}
$$

Due to Lemma 6 (ii), $\widetilde{\mathrm{Q}}_{1} \widetilde{\mathrm{Q}}_{2}<\overline{\mathrm{R}}_{2}$, and it follows that $\mathrm{c}_{2}^{\mathrm{i}}\left(\widetilde{\mathrm{Q}}_{1}, \widetilde{\mathrm{Q}}_{2}\right)>\mathrm{c}_{2}^{\mathrm{i}}\left(\overline{\mathrm{Q}}_{1}, \overline{\mathrm{R}}_{2}\right)$. $\quad$ Q.E.D.

\section{Proof of Proposition 3:}

We show that for an individual of type $L$, the optimal consumption bundles $\left(c_{1}^{i}, c_{2}^{i}\right)$ in both regimes lie to the right of the point of intersection of the consumption possibility curves (3.14) and (3.15), while the opposite holds true for an individual of type $\mathrm{H}$. From this we conclude that an individual of type $L$ prefers the simultaneous regime with prices $\bar{Q}_{1}, \bar{R}_{2}$, while an individual of type $\mathrm{H}$ prefers the sequential regime with prices $\widetilde{\mathrm{Q}}_{1}, \widetilde{\mathrm{Q}}_{2}$. 
We calculate the point of intersection of the possibility curves of an individual $i=L, H$, under both regimes by solving (3.14) and (3.15) for $c_{1}^{i}$ and substituting (3.5), which gives

$$
c_{1}^{i}(S) \equiv \frac{\bar{R}_{2}-\widetilde{Q}_{1} \widetilde{Q}_{2}}{\widetilde{Q}_{1}\left(\bar{R}_{2}-\overline{\mathrm{Q}}_{1} \widetilde{\mathrm{Q}}_{2}\right)}\left(1+\pi_{2}^{i}\right) X^{i}
$$

As a preparation, we show in step (i) that $c_{1}^{L}\left(\widetilde{Q}_{1}, \widetilde{Q}_{2}\right)-c_{1}^{L}(S)>0$ and in step (ii) that $\mathrm{c}_{1}^{\mathrm{H}}\left(\overline{\mathrm{Q}}_{1}, \overline{\mathrm{R}}_{2}\right)-\mathrm{c}_{1}^{\mathrm{H}}(\mathrm{S})<0$.

(i) By use of (A42) and (A46) for $\mathrm{i}=\mathrm{L}$, we calculate the difference $c_{1}^{\mathrm{L}}\left(\widetilde{\mathrm{Q}}_{1}, \widetilde{\mathrm{Q}}_{2}\right)-\mathrm{c}_{1}^{\mathrm{L}}(\mathrm{S})$, which can be written as

$$
\mathrm{c}_{1}^{\mathrm{L}}\left(\widetilde{\mathrm{Q}}_{1}, \widetilde{\mathrm{Q}}_{2}\right)-\mathrm{c}_{1}^{\mathrm{L}}(\mathrm{S})=\frac{\mathrm{X}^{\mathrm{L}}}{\widetilde{\mathrm{Q}}_{1}\left(\overline{\mathrm{R}}_{2}-\overline{\mathrm{Q}}_{1} \widetilde{\mathrm{Q}}_{2}\right)}\left[\left(\widetilde{\mathrm{Q}}_{1}-\overline{\mathrm{Q}}_{1}\right)+\pi_{2}^{\mathrm{L}}\left(\widetilde{\mathrm{Q}}_{1}-\frac{\overline{\mathrm{R}}_{2}}{\widetilde{\mathrm{Q}}_{2}}\right)\right]
$$

First note from Lemma 6 (ii) that $\overline{\mathrm{R}}_{2}-\widetilde{\mathrm{Q}}_{1} \widetilde{\mathrm{Q}}_{2}>0$ and $\overline{\mathrm{Q}}_{1}<\widetilde{\mathrm{Q}}_{1}$, hence $\overline{\mathrm{R}}_{2}-\overline{\mathrm{Q}}_{1} \widetilde{\mathrm{Q}}_{2}>0$. It follows that $c_{1}^{L}\left(\widetilde{Q}_{1}, \widetilde{Q}_{2}\right)-c_{1}^{L}(S)$ has the same sign as the term in the squared bracket on the RHS of (A47), which we denote by $\Omega \equiv\left(\widetilde{\mathrm{Q}}_{1}-\overline{\mathrm{Q}}_{1}\right)+\pi_{2}^{\mathrm{L}}\left(\widetilde{\mathrm{Q}}_{1}-\overline{\mathrm{R}}_{2} / \widetilde{\mathrm{Q}}_{2}\right)$. By use of (A39) and (A41), together with (A36) and $\bar{\rho}_{2} / \bar{\rho}_{1}=\pi_{2}^{\mathrm{H}} / \pi_{2}^{\mathrm{L}}$ [immediate by use of (3.11) and (3.13)], $\Omega$ can be rewritten - after some easy transformations - as

$$
\Omega=\lambda\left[\left(\frac{1+\pi_{2}^{\mathrm{H}}}{1+\pi_{2}^{\mathrm{L}}}-1\right)\left(1+\frac{\pi_{2}^{\mathrm{H}}}{\pi_{2}^{\mathrm{L}}} \bar{\rho}_{1}\right)+\pi_{2}^{\mathrm{L}}\left(\frac{1+\pi_{2}^{\mathrm{H}}}{1+\pi_{2}^{\mathrm{L}}}-\frac{\pi_{2}^{\mathrm{H}}}{\pi_{2}^{\mathrm{L}}}\right)\left(1+\bar{\rho}_{1}\right)\right]
$$

where

$$
\lambda \equiv \frac{\left(\pi_{1}^{\mathrm{H}}-\pi_{1}^{\mathrm{L}}\right) \bar{\rho}_{1}}{\left(1+\tilde{\rho}_{1}\right)\left(1+\bar{\rho}_{1}\right)\left(1+\bar{\rho}_{2}\right)},
$$

which is positive, as $\pi_{1}^{\mathrm{H}}>\pi_{1}^{\mathrm{L}}$. Further computations of (A48) yields

$$
\Omega=\lambda\left[\left(\frac{1+\pi_{2}^{\mathrm{H}}}{1+\pi_{2}^{\mathrm{L}}}-1+\pi_{2}^{\mathrm{L}} \frac{1+\pi_{2}^{\mathrm{H}}}{1+\pi_{2}^{\mathrm{L}}}-\pi_{2}^{\mathrm{H}}\right)+\bar{\rho}_{1}\left(\frac{1+\pi_{2}^{\mathrm{H}}}{1+\pi_{2}^{\mathrm{L}}}-\frac{\pi_{2}^{\mathrm{H}}}{\pi_{2}^{\mathrm{L}}}+\pi_{2}^{\mathrm{L}} \frac{1+\pi_{2}^{\mathrm{H}}}{1+\pi_{2}^{\mathrm{L}}}-\pi_{2}^{\mathrm{H}}\right)\right],
$$

which reduces to (note that the first term in the parenthesis on the RHS of (A40) is equal to zero)

$$
\Omega=\lambda \frac{\bar{\rho}_{1}}{\left(1+\pi_{2}^{\mathrm{L}}\right) \pi_{2}^{\mathrm{L}}}\left(\pi_{2}^{\mathrm{H}}-\pi_{2}^{\mathrm{L}}\right)^{2} .
$$

From (A51), together with (A49), it is immediate that $\Omega>0$, which proves that $\mathrm{c}_{1}^{\mathrm{L}}\left(\widetilde{\mathrm{Q}}_{1}, \widetilde{\mathrm{Q}}_{2}\right)-\mathrm{c}_{1}^{\mathrm{L}}(\mathrm{S})>0$. 
(ii) By use of (A43) and (A46) for $\mathrm{i}=\mathrm{H}$, we calculate the difference $c_{1}^{\mathrm{H}}\left(\overline{\mathrm{Q}}_{1}, \overline{\mathrm{R}}_{2}\right)-\mathrm{c}_{1}^{\mathrm{H}}(\mathrm{S})$, which can be written as

$$
\mathrm{c}_{1}^{\mathrm{H}}\left(\overline{\mathrm{Q}}_{1}, \overline{\mathrm{R}}_{2}\right)-\mathrm{c}_{1}^{\mathrm{H}}(\mathrm{S})=\frac{\widetilde{\mathrm{Q}}_{2} \mathrm{X}^{\mathrm{H}}}{\overline{\mathrm{Q}}_{1} \widetilde{\mathrm{Q}}_{1}\left(\overline{\mathrm{R}}_{2}-\overline{\mathrm{Q}}_{1} \widetilde{\mathrm{Q}}_{2}\right)}\left[\left(\widetilde{\mathrm{Q}}_{1}-\overline{\mathrm{Q}}_{1}\right) \frac{\overline{\mathrm{R}}_{2}}{\widetilde{\mathrm{Q}}_{2}}+\pi_{2}^{\mathrm{H}} \overline{\mathrm{Q}}_{1}\left(\frac{\overline{\mathrm{R}}_{2}}{\widetilde{\mathrm{Q}}_{2}}-\widetilde{\mathrm{Q}}_{1}\right)\right]
$$

From part (i) of this proof we know that $\bar{R}_{2}-\bar{Q}_{1} \widetilde{Q}_{2}>0$. It follows that $c_{1}^{H}\left(\bar{Q}_{1}, \bar{R}_{2}\right)-c_{1}^{H}(S)$ has the same sign as the term in the squared brackets on the RHS of (A52), which we denote by $\Phi \equiv\left(\widetilde{\mathrm{Q}}_{1}-\overline{\mathrm{Q}}_{1}\right) \overline{\mathrm{R}}_{2} / \widetilde{\mathrm{Q}}_{2}+\pi_{2}^{\mathrm{H}} \overline{\mathrm{Q}}_{1}\left(\overline{\mathrm{R}}_{2} / \widetilde{\mathrm{Q}}_{2}-\widetilde{\mathrm{Q}}_{1}\right)$. By use of (A39) - (A41), together with (A36) and $\bar{\rho}_{2} / \bar{\rho}_{1}=\pi_{2}^{\mathrm{H}} / \pi_{2}^{\mathrm{L}}$ [see part (i)], $\Phi$ can be rewritten - after some easy steps of transformations - as

$$
\Phi=\lambda\left[\left(\frac{1+\pi_{2}^{\mathrm{H}}}{1+\pi_{2}^{\mathrm{L}}}-1\right)\left(\pi_{1}^{\mathrm{L}}+\frac{\pi_{1}^{\mathrm{H}} \pi_{2}^{\mathrm{H}}}{\pi_{2}^{\mathrm{L}}} \bar{\rho}_{1}\right)+\pi_{2}^{\mathrm{H}}\left(\pi_{1}^{\mathrm{L}}+\pi_{1}^{\mathrm{H}} \bar{\rho}_{1}\right)\left(\frac{1+\pi_{2}^{\mathrm{H}}}{1+\pi_{2}^{\mathrm{L}}}-\frac{\pi_{2}^{\mathrm{H}}}{\pi_{2}^{\mathrm{L}}}\right)\right]
$$

Further computations of (A53) yields

$$
\begin{aligned}
\Phi=\lambda & {\left[\frac{\pi_{1}^{\mathrm{L}}\left(1+\pi_{2}^{\mathrm{H}}\right)}{1+\pi_{2}^{\mathrm{L}}}-\pi_{1}^{\mathrm{L}}+\frac{\pi_{1}^{\mathrm{L}} \pi_{2}^{\mathrm{H}}\left(1+\pi_{2}^{\mathrm{H}}\right)}{1+\pi_{2}^{\mathrm{L}}}-\frac{\pi_{1}^{\mathrm{L}} \pi_{2}^{\mathrm{H}} \pi_{2}^{\mathrm{H}}}{\pi_{2}^{\mathrm{L}}}+\right.} \\
& \left.+\frac{\pi_{1}^{\mathrm{H}} \pi_{2}^{\mathrm{H}}}{\pi_{2}^{\mathrm{L}}} \bar{\rho}_{1}\left(\frac{1+\pi_{2}^{\mathrm{H}}}{1+\pi_{2}^{\mathrm{L}}}-1+\pi_{2}^{\mathrm{L}} \frac{1+\pi_{2}^{\mathrm{H}}}{1+\pi_{2}^{\mathrm{L}}}-\pi_{2}^{\mathrm{H}}\right)\right]
\end{aligned}
$$

which reduces to (note that the last term in the parenthesis on the RHS of (A54) is equal to zero)

$$
\Phi=-\lambda \frac{\pi_{1}^{\mathrm{L}}}{\left(1+\pi_{2}^{\mathrm{L}}\right) \pi_{2}^{\mathrm{L}}}\left(\pi_{2}^{\mathrm{H}}-\pi_{2}^{\mathrm{L}}\right)^{2} .
$$

From (A55), together with (A49), it is immediate that $\Phi<0$, which proves that $\mathrm{c}_{1}^{\mathrm{H}}\left(\overline{\mathrm{Q}}_{1}, \overline{\mathrm{R}}_{2}\right)-\mathrm{c}_{1}^{\mathrm{H}}(\mathrm{S})<0$.

Finally we know from Lemma 7 that $\mathrm{c}_{1}^{\mathrm{H}}\left(\widetilde{\mathrm{Q}}_{1}, \widetilde{\mathrm{Q}}_{2}\right)<\mathrm{c}_{1}^{\mathrm{H}}\left(\overline{\mathrm{Q}}_{1}, \overline{\mathrm{R}}_{2}\right)$, which together with $\mathrm{C}_{1}^{\mathrm{H}}\left(\overline{\mathrm{Q}}_{1}, \overline{\mathrm{R}}_{2}\right)<\mathrm{C}_{1}^{\mathrm{H}}(\mathrm{S})$ implies that for both regimes consumption lies to the left of the point of intersection $\mathrm{c}_{1}^{\mathrm{H}}(\mathrm{S})$ of the consumption possibility curves of both regimes. As to the left of $\mathrm{C}_{1}^{\mathrm{H}}(\mathrm{S})$ the consumption set is larger for the sequential regime than for the simultaneous regime, it follows that the type- $\mathrm{H}$ individuals are better off with the sequential regime.

Similarly, $c_{1}^{\mathrm{L}}\left(\overline{\mathrm{Q}}_{1}, \overline{\mathrm{R}}_{2}\right)>\mathrm{c}_{1}^{\mathrm{L}}\left(\widetilde{\mathrm{Q}}_{1}, \widetilde{\mathrm{Q}}_{2}\right)$ and $\mathrm{c}_{1}^{\mathrm{L}}\left(\widetilde{\mathrm{Q}}_{1}, \widetilde{\mathrm{Q}}_{2}\right)>\mathrm{c}_{1}^{\mathrm{L}}(\mathrm{S})$ (see step (i) and and Lemma 7) imply, by analogous reasoning, that the type-L individuals are better off with the simultaneous regime.

Q.E.D. 


\section{References}

Abel, Andrew B. (1986), Capital Accumulation and Uncertain Lifetime with Adverse Selection, Econometrica 54, 1079-1097.

Brugiavini, Agar (1993), Uncertain resolution and the timing of annuity purchases, Journal of Public Economics, 31-62.

Brunner, Johann K. and Susanne Pech (2005), Adverse selection in the annuity market when payoffs vary over the time of retirement, working paper No. 0030, forthcoming in: Journal of Institutional and Theoretical Economics, Vol. 161(1), 155-183.

Eckstein, Zvi, Martin Eichenbaum and Dan Peled (1985), Uncertain Lifetimes and the Welfare Enhancing Properties of Annuity Markets and Social Security, Journal of Public Economics 26, 303-326.

Finkelstein, Amy and James M. Poterba (2002), Selection Effects in the United Kingdom Individual Annuities Market, Economic Journal 112(476), 28-50.

Friedman, Benjamin M., and Mark J. Warshawsky (1990), The Cost of Annuities: Implications for Saving Behaviour and Bequests, Quaterly Journal of Economics 105, 135-154.

Mitchell, Olivia S., James M. Poterba, Mark J. Warshawsky and Jeffrey R. Brown (1999), New Evidence on the Money's Worth of Individual Annuities, American Economic Review 89, 1299-1318.

Pauly, Mark V. (1974), Overinsurance and Public Provision of Insurance: The Roles of Moral Hazard and Adverse Selection, Quarterly Journal of Economics 88, 44-62.

Pech, S. (2004), Tax incentives for private life annuities and the social security reform: effects on consumption and on adverse selection, FinanzArchiv, Vol. 60 (4), 556-592.

Poterba, James M. (1997), "The History of Annuities in the United States", NBER Working Paper 6001.

Rothschild, Michael and Josef Stiglitz (1976), Equilibrium in Competitive Insurance Markets: An Essay on the Economics of Imperfect Information, Quarterly Journal of Economic 90, 629-649.

Townley, Peter G. C. and Robin W. Boadway (1988), Social Security and the Failure of Annuity Markets, Journal of Public Economics 35, 75-96.

Walliser, Jan (2000), Adverse Selection in the Annuities Market and the Impact of Privatizing Social Security, Scandinavian Journal of Economics 102, 373-393.

Yaari, Menahem E. (1965), Uncertain Lifetime, Life Insurance, and the Theory of the Consumer, Review of Economic Studies 32, 137-150.

Yagi, Tadashi and Yasuyuki Nishigaki (1993), The Inefficiency of Private Constant Annuities, The Journal of Risk and Insurance 60, 385-412. 